\title{
Development of a Fuzzy Variable Rate Irrigation Control Sys- tem Based on Remote Sensing Data to Fully Automate Center Pivots
}

\author{
Willians R. Mendes ${ }^{1 *}$, Salah Er-Raki ${ }^{2,3}$, Derek M. Heeren ${ }^{4}$, Ritaban Dutta $^{5}$, Fábio M. U. Araújo ${ }^{6}$
}

1 Federal Institute of Education, Science and Technology of Mato Grosso (IFMT/PDL), Mato Grosso, Brazil; willians.mendes@pdl.ifmt.edu.br

2 ProcEDE, Laboratoire des Procédés pour I'Energie Durable et Environnement, Faculté des Sciences et Techniques Guéliz, Cadi Ayyad University, Marrakech, Morocco ; s.erraki@uca.ma

3 Center for Remote Sensing Application, Mohammed VI Polytechnic University, Ben Guerir; Morocco

4 University of Nebraska-Lincoln, 241 L.W. Chase Hall, 3605 Fair St., Lincoln, NE, USA; derek.heeren@unl.edu

5 Data61, The Commonwealth Scientific and Industrial Research Organization (CSIRO), Tasmania 7004, AUS; ritaban.dutta@csiro.au

6 Federal University of Rio Grande do Norte, University Campus Lagoa Nova. Rio Grande do Norte, Brazil; meneghet@dca.ufrn.br

* Correspondence: willians.mendes@pdl.ifmt.edu.br; Tel.: +55 659 8406-4868.

\begin{abstract}
Growing agricultural demands for global population are unlocking the path to developing innovative solutions for efficient water management. Herein, an intelligent variable rate irrigation system (fuzzy-VRI) is proposed for rapid decision making to achieve optimized irrigation in various delimited zones. The proposed system automatically creates irrigation maps for a center pivot irrigation system for a variable-rate application of water. Primary inputs are spatial imagery on remotely sensed soil moisture (SSM), soil adjusted vegetation index (SAVI), canopy temperature (CT), and nitrogen content (NI). To eliminate localized issues with soil characteristics, we used the crop nitrogen content map to provide a focused insight on issues related to water shortage. The system relates these inputs to set reference values for the rotation speed controllers and individual openings of each central pivot sprinkler valve. The results showed that the system can detect and characterize spatial variability of the crop and further, the fuzzy logic solved the uncertainties of an irrigation system and defined a control model for high-precision irrigation. The proposed approach is validated through the comparison between the recommended irrigation and actual irrigation at two field sites, and the results showed that the developed approach gives an accurate estimation of irrigation with a reduction in the volume of irrigated water of up to $27 \%$ in some cases. Future research should implement the fuzzy-VRI real-time during field trials in order to quantify its effect on irrigation use, yield, and water use efficiency.
\end{abstract}

Keywords: Remote sensing data; variable rate irrigation; irrigation management; fuzzy systems; decision support tools; intelligent center pivot

\section{Introduction}

The challenge of increasing agricultural production [1], especially irrigated agriculture which represents a major contribution to food security [2], can probably only be overcome using new technologies. Historically, irrigation development has been shown to improve crop water productivity, and advancements in technology have increased irrigation application efficiency [3]. Moving forward, continued advancements in technology will be important, including those which seek to optimize input use efficiency at a sub-field scale; in this context, spatiotemporal yield variability has been found to be driven largely by location, vegetation condition, soil water content, and topography [4]. For example, 
variable rate irrigation (VRI) technology is a tool employed in crop areas, which are divided into management zones (MZs), to provide optimal water volumes based on field variability [5].

Recent innovations in wireless sensor and data communication network technologies, as well as advances in mobile technologies, provide crucial opportunities to develop management tools and decision-support systems for improving irrigation efficiency and productivity [6].

VRI was recently developed commercially to control the speed and sprinklers of center pivots to apply water differentially in each MZ [7]. Center pivot irrigation systems (CPISs) are highly automated, rendering them ideal for site-specific management. These systems were modified for controlling the lateral rotation speed and sprinkler flow rate in applying water and agricultural inputs according to field variability [8-15]. Effective VRI systems collect different types of information, including hydrological and meteorological data, as well as crop and soil type, to accurately determine the amount, time, and location of irrigation [16].

Remote sensing data can be used to measure the parameters that affect the spatial variability of a crop [17-19]. Additionally, the information obtained can be used to improve crop quality, monitor irrigation and fertilization processes and manage weeds. Thus, new technological approaches are required for effective water management decision-making to optimize water use. Therefore, tools that use knowledge representation and reasoning to address inaccuracies are a viable alternative.

Big data holds viable prospects for irrigated agriculture, and studies have shown that it can significantly improve in precision irrigation systems [20]. Big data represents the information assets that are characterized by high volumes, high-speed processing, and a variety of inputs [21]. However, the ultimate challenge of an environmental and agricultural decision-support system is overcoming the uncertainty associated with data quality, automatic knowledge validation, and improved efficiency of the decision-making process [22].

Moving in this direction, several advanced control strategies have been proposed over the last decades (see, e.g., the survey [23] and references therein). Over the last decades MPC (also known as receding horizon control or moving horizon control) has become an important strategy for finding control policies for complex, dynamic systems [24]. Although, they are providing an accurate tool for modelling irrigation systems, these models are not always adequate for control design due to its complexity and require approximations. Even if simplified models are used, it is expensive to perform the experiments in order to get the data needed for identification purposes [25].

In real-life situations, a decision-maker (DM) is often faced with the unavailability or costly acquisition of information necessary to build a classic decision model, leading to the adoption of inaccurate models. A useful approach for dealing with knowledge representation and reasoning to address inaccuracies is the fuzzy set theory. This theory has been considered an effective way to model real-life decision problems [26].

A fuzzy rule system is useful in irrigation control and can be easily adapted and programmed in commercial microcontrollers. This system has been used to estimate daily reference evapotranspiration with fewer parameters for irrigation planning [27]. In [28], a crop water stress index based on fuzzy logic rules was modeled and tested on real data obtained using traditional methods. A fuzzy inference system (FIS) such as those developed by [29-32] use fuzzy logic to mimic human operators and monitor and control the duration of irrigation, yielding results that are superior to those of traditional control systems. One of the advantages of using fuzzy decision-making systems, especially in this context, is that only the main data used to determine irrigation are necessary, rather than all the available information [33].

The main goal of a decision-support system is to estimate the amount of water to be applied using input variables that are common in irrigation systems, including climate data, soil moisture, type of crop, and stage of crop development. However, no study has evaluated variables directly related to the application equipment. Studies have generally 
focused on developing VRI technologies and assessing their performances. Meanwhile, there is potential for improving strategies for control equipment used for applying agricultural inputs, for example, the outputs of a decision-support system and the input information of the controller. The actual irrigation volume is based on water requirements; nonetheless, this parameter is not the only practical factor in irrigation.

Therefore, to yield accurate results, we propose an intelligent variable rate irrigation system (fuzzy-VRI) for efficient decision making to achieve optimized irrigation. Further, the main component of the proposed system is fuzzy logic, which can set reference values for the rotation speed and degree of opening of each sprinkler valve of a center pivot. This model makes decisions on irrigation requirements using available remote sensing data. Therefore, it is expected that the system will aid intelligent irrigation systems to efficiently create optimal control maps for a center pivots.

\section{Materials and Methods}

The proposed fuzzy-VRI system was validated using two case studies, each of which was performed in a crop area using a conventional irrigation management strategy. The remote sensing and actual data for comparison were acquired through partnerships with commercial companies and the University of Nebraska-Lincoln.

\subsection{Study Areas}

A partnership was established with Sistema Irriga ${ }^{\circledR} 1$ to access actual irrigation data of commercial crops. The first case study (GPS coordinates $12^{\circ} 03^{\prime} 30.7^{\prime \prime} \mathrm{S}, 56^{\circ} 06^{\prime} 58.5^{\prime \prime} \mathrm{W}$ ) was a commercial farm with approximately 100 hectares located in Ipiranga do Norte, Mato Grosso, Brazil. This site was planted with beans on June 15, 2018, and harvested on September 15, 2018, which is periodically irrigated (Table 1).

Table 1. Dates and amounts of irrigation events at the study site located in Ipiranga do Norte, Mato Grosso, Brazil, along with dates of satellite imagery (retrieved from the i-ekbase database) Source: Irrigation management company - Irriga ${ }^{\circledR}$ System, for the 2018 growing season. 1

\begin{tabular}{|c|c|c|c|c|}
\hline \multicolumn{5}{|c|}{ Dates } \\
\hline Satellite overpass & $\begin{array}{l}\text { Beginning of irri- } \\
\text { gation }\end{array}$ & $\begin{array}{c}\text { End of irriga- } \\
\text { tion }\end{array}$ & $\begin{array}{l}\text { Actual irriga- } \\
\text { tion depth } \\
{[\mathrm{mm}]}\end{array}$ & $\begin{array}{c}\text { Duration of } \\
\text { one full turn } \\
{[\mathrm{h}]}\end{array}$ \\
\hline \multirow{4}{*}{ June 17} & June 15 & June 16 & 6.1 & 14 \\
\hline & June 17 & June 18 & 6.1 & 14 \\
\hline & June 23 & June 24 & 6.1 & 14 \\
\hline & June 25 & June 26 & 6.1 & 14 \\
\hline \multirow{2}{*}{ June 27} & June 27 & June 28 & 6.1 & 14 \\
\hline & June 30 & July 1 & 6.1 & 14 \\
\hline \multirow{8}{*}{ July 5} & July 3 & July 4 & 6.1 & 14 \\
\hline & July 7 & July 8 & 8.7 & 20 \\
\hline & July 10 & July 11 & 8.7 & 20 \\
\hline & July 12 & July 13 & 8.7 & 20 \\
\hline & July 14 & July 15 & 8.7 & 20 \\
\hline & July 16 & July 17 & 7.2 & 16.5 \\
\hline & July 19 & July 20 & 7.2 & 16.0 \\
\hline & July 25 & July 26 & 10.2 & 24 \\
\hline July 29 & July 27 & July 29 & 12.2 & 28 \\
\hline
\end{tabular}

${ }^{1}$ https://www.sistemairriga.com.br/ 


\begin{tabular}{llllc}
\hline & July 30 & August 1 & 13.5 & 31 \\
\multirow{2}{*}{ August 6 } & August 2 & August 4 & 13.6 & 31.5 \\
& August 6 & August 8 & 13.6 & 31.5 \\
& August 10 & August 12 & 13.6 & 31.5 \\
& August 12 & August 14 & 13.6 & 31.5 \\
August 14 & August 14 & August 16 & 13.6 & 31.5 \\
& August 16 & August 17 & 8.9 & 20.5 \\
& August 18 & August 20 & 13.6 & 31.5 \\
August 22 & August 20 & August 22 & 13.6 & 31.5 \\
August 27 & August 28 & August 30 & 13.6 & 31.5 \\
\hline
\end{tabular}

The irrigation system for this study area was based on the water balance method, and it used the Penman-Monteith [34] model to estimate evapotranspiration. Hence, the estimates were generalized for the entire area, and irrigation was performed uniformly with the same depth across the crop. As the irrigation depth increased, the speed decreased, and the time to complete one full also increased. This type of control is common in commercial irrigation system in Brazil (Table 1). Therefore, as the crop developed, the water requirements and volume of irrigation increased, consequently increasing the time that it took the pivot to complete a full turn. This approach resulted in irrigation events that lasted more than one day, i.e., started on a specific date and finished on the following day.

Another partnership was established with the University of Nebraska-Lincoln to access field data from [17]. The cultivated area belongs to the University's Water Resources Field Laboratory and is located near the city of Brule, Nebraska, United States. The second case study was an experimental area (GPS coordinates: $41^{\circ} 01^{\prime} 44.4^{\prime \prime} \mathrm{N}, 101^{\circ} 58^{\prime} 15.6^{\prime \prime} \mathrm{W}$ ) with approximately 50 hectares. The site has a model 8500 Zimmatic (Lindsay Corporation, Omaha, NE, USA) center pivot equipped with a VRI system, including an individual nozzle control [17] [21]. More details about the description of two sites are provided as supplement information. The irrigation data provided by the University of Nebraska research team are summarized in Table 2.

Table 2. Irrigation dates and depths in Brule, Nebraska, United States, along with dates of satellite imagery (retrieved from the i-ekbase database) which were used in the analysis, for the 2016 growing season.

\begin{tabular}{ccccc}
\hline & Dates & & \multicolumn{2}{c}{ Actual irrigation depth } \\
\hline Satellite over- & Beginning of irriga- & End of irrigation & Uniform irri- \\
pass & tion event & event & Vation [mm] & VRI-RS [mm] \\
& May 24 & May 25 & 12.7 & $12.7^{*}$ \\
June 24 & June 23 & June 25 & 15.2 & $15.2^{*}$ \\
& July 4 & July 6 & 15.2 & $15.2^{*}$ \\
July 10 & July 7 & July 9 & 20.6 & $20.56^{*}$ \\
July 10 & July 12 & July 14, & 20.6 & $20.6^{*}$ \\
& July 15 & July 16 & 20.6 & $20.6^{*}$ \\
July 26 & July 17 & July 19 & 20.6 & $20.6^{*}$ \\
& July 24 & July 26 & 20.6 & $20.6^{*}$ \\
& July 31 & August 2 & 20.6 & $20.6^{*}$ \\
August 11 & August 5 & August 7 & 20.6 & $20.6^{*}$ \\
August 19 & August 10 & August 12 & 25.4 & $25.4^{*}$ \\
& August 20 & August 22 & 25.4 & $25.4^{*}$ \\
& August 24 & August 26 & 25.4 & $5.1-20.3^{* *}$ \\
September 12 & August 31 & September 2 & 25.4 & $10.2-25.4^{* *}$ \\
\hline
\end{tabular}




\begin{tabular}{ccccc}
\hline September 20 & September 19 & September 21 & 15.2 & $25.4^{*}$ \\
& September 23 & September 25 & 13.6 & 31.5 \\
\hline & *Irrigation depths were similar between management zones; these values can be observed in the \\
& list provided by the researchers (Annex 01). ${ }^{* *}$ Variable irrigation depth values found in manage- \\
& ment zones. Source: Adapted from [17].
\end{tabular}

\subsection{Remote Sensing Data}

The remote sensing data from the crop areas in each study site were requested from a specialized company. Hence, a partnership was established with Intelligent Environmental Knowledgebase (i-ekbase ${ }^{\mathrm{TM} 2}$ ), which allowed for free but limited use of an online tool [22]. I-ekbase also processed these images; thus, the input variables were not processed in this present study. Based on the crop location and the dates of analysis, I-ekbase acquired the images using Landsat and Sentinel satellites, stored them in a database, and processed them using algorithms.

The study variables were selected with the help of field specialists based on data available on the i-ekbase system platform that would best describe the soil-plant-atmosphere continuum for the intelligent irrigation system. Therefore, the selected parameters for characterizing the development and hydric status of the crop are: Soil-adjusted vegetation index, SAVI (\%); Canopy temperature, CT $\left({ }^{\circ} \mathrm{C}\right)$; Surface soil moisture, SSM (\%) and Nitrogen index, NI (\%). As proper data selection was fundamental at this stage for accurate results, the company provided remote sensing data derived from satellite images via the online tool (https://www.iekbase.com/hot-spots-monitoring-).

While the crop water stress index (calculated from canopy temperature and other micrometeorological data) is often used in irrigation research instead of directly using canopy temperature, calculating crop water stress index was outside the scope of this research. Recent research has invested simpler canopy temperature indices for triggering irrigation [35]. Future research should investigate incorporating the crop water stress index or other thermal indices into the fuzzy VRI system.

The vegetation index (SAVI) was higher in irrigated areas than in non-irrigated areas. This type of spectral response was expected because irrigated areas tend to have greater vegetative vigor due to their higher gas exchange between leaves and the atmosphere, which results in a higher absorption of visible light for photosynthesis and healthier behavior [36-37]. Remote sensing can also provide soil moisture data only from soil layers near the surface $(0-5 \mathrm{~cm})$ [38]. While it certainly ideal to measure soil moisture for the entire root zone, this typically requires in situ sensors while remote sensing data is more readily available.

Other research has used remotely sensed surface soil moisture to determine effective hydraulic soil parameters and estimate soil moisture content for the entire root zone [3940]. The development of the plant root system is strongly affected by the nitrogen content of the soil. Therefore, nitrogen detection using remote sensing enables a superficial but quick detection of water deficit [41-44].

\subsection{Fuzzy System}

To create a control map for each study site, an artificial intelligent (AI) system was developed to infer the rotation speed of the center pivot and degree of opening of the valves in each irrigation area. The AI technique chosen to integrate the decision-making system was a fuzzy system (Figure 1).

\footnotetext{
2 https://www.iekbase.com/
} 


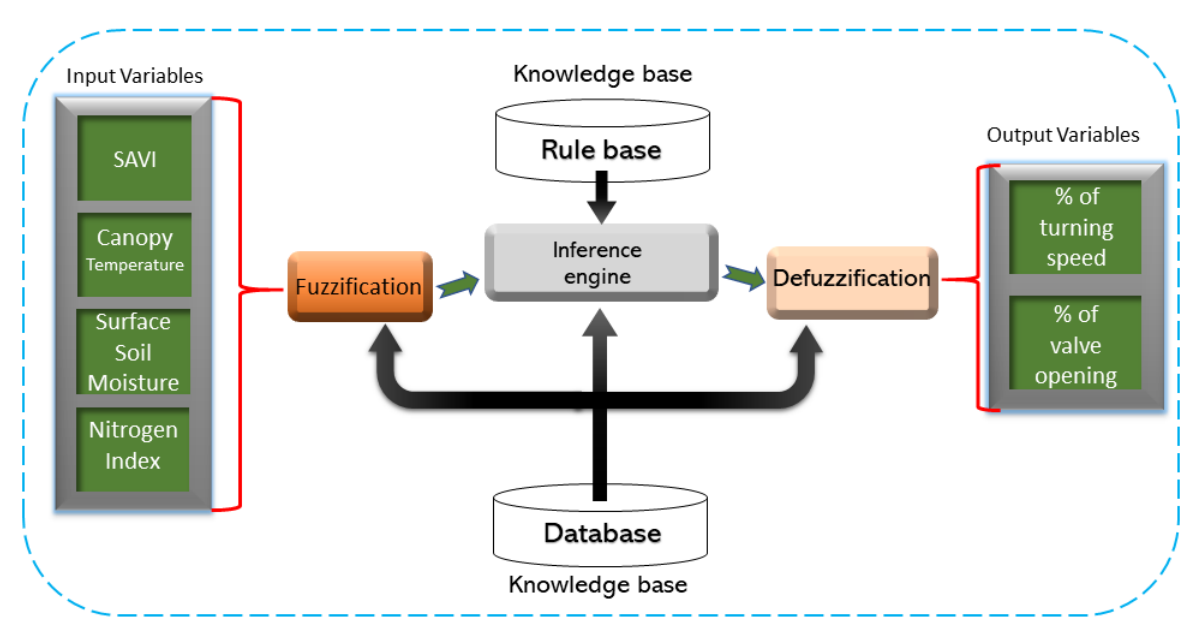

Figure 1. Structure of the fuzzy system.

The critical component of this process is a fuzzy system with a Mamdani inference mechanism [45]. The design and construction of the system is presented in four stages: fuzzification of input variables, construction of rule base, inference engine, and defuzzification of output variables.

\subsubsection{Fuzzification}

Fuzzification is the conversion of numerical values into fuzzy linguistic quantifiers [46], and it is performed using membership functions (MFs). Each MF evaluates the adequacy of a specific fuzzy qualifier for describing a linguistic variable. MFs were used to fuzzify the input data and were defined by interpreting the satellite data provided by iekbase. Triangular or trapezoidal MFs were chosen for construction simplicity [47].

Five linguistic variables were chosen for each input variable (NI, SAVI, SSM, and CT) as follows: very low $(\mathrm{VL})$, low $(\mathrm{L})$, medium $(\mathrm{M})$, high $(\mathrm{H})$, and very high $(\mathrm{VH})$. The triangular MF was divided equally into grid partitions [48]. The method described in [49] and advice of a field specialist were used to describe the linguistic variables of each input variable.

\subsubsection{Fuzzification of input variables of a commercial farm in Mato Grosso, Brazil}

Remote sensing data were requested from i-ekbase after obtaining irrigation data from the irrigation system. The input variables (Table 3) were analyzed for eight dates.

Table 3. Maximum and minimum values of input variables for the planting area in Ipiranga do Norte for 2018 agricultural season.

\begin{tabular}{|c|c|c|c|c|c|c|c|c|}
\hline \multirow[t]{2}{*}{ Date } & \multicolumn{2}{|c|}{$\begin{array}{l}\text { Nitrogen index } \\
(\%)\end{array}$} & \multicolumn{2}{|c|}{$\begin{array}{c}\text { Soil-adjusted } \\
\text { vegetation in- } \\
\text { dex }(\%)\end{array}$} & \multicolumn{2}{|c|}{$\begin{array}{c}\text { Surface soil } \\
\text { moisture (\%) }\end{array}$} & \multicolumn{2}{|c|}{$\begin{array}{l}\text { Canopy tem- } \\
\text { perature }\left({ }^{\circ} \mathrm{C}\right)\end{array}$} \\
\hline & Min & Max & Min & Max & Min & Max & Min & Max \\
\hline June 17 & 0.01 & 4.19 & 0.1 & 32.9 & 8.3 & 25.6 & 10.9 & 24.3 \\
\hline June 27 & 0.01 & 4.19 & 1.1 & 49.8 & 0.1 & 15.5 & 25.4 & 31.3 \\
\hline July 5 & 2.11 & 3.98 & 8.5 & 48.6 & 0.4 & 12.5 & 27.8 & 33.0 \\
\hline July 29 & 1.84 & 2.60 & 31.7 & 70.9 & 0.1 & 9.9 & 24.2 & 29.4 \\
\hline $\begin{array}{c}\text { August } \\
6\end{array}$ & 1.85 & 2.54 & 30.4 & 73.7 & 0.1 & 9.6 & 21.9 & 24.9 \\
\hline $\begin{array}{c}\text { August } \\
14\end{array}$ & 1.82 & 2.96 & 23.8 & 80.1 & 4.9 & 14.3 & 25.2 & 31.0 \\
\hline
\end{tabular}




\begin{tabular}{ccccccccc}
\hline $\begin{array}{c}\text { August } \\
22\end{array}$ & 1.83 & 2.48 & 30.9 & 77.1 & 8.7 & 14.3 & 22.4 & 27.3 \\
$\begin{array}{c}\text { August } \\
27\end{array}$ & 1.83 & 2.79 & 26.7 & 75.4 & 7.5 & 18.1 & 23.3 & 32.0 \\
\hline
\end{tabular}

MFs were initially constructed using the grid partition method. Hence, the entire universe of discourse was established by selecting the maximum values of each input variable. The fuzzy sets for each variable after making system adjustments are shown in Figures 2 .

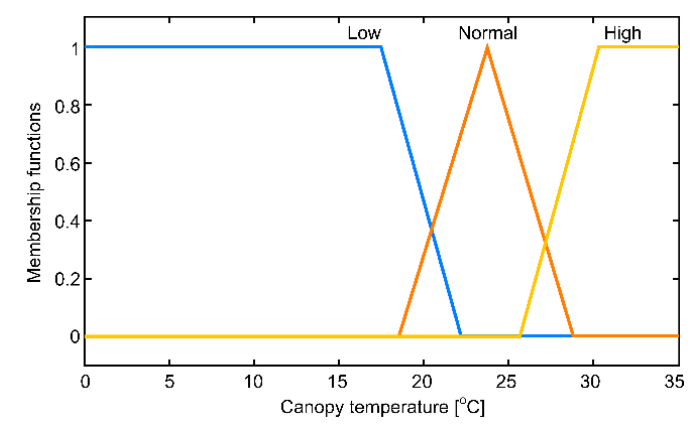

a)

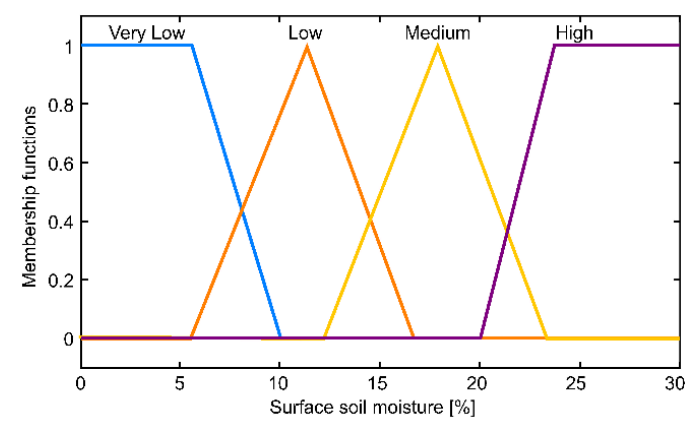

c)

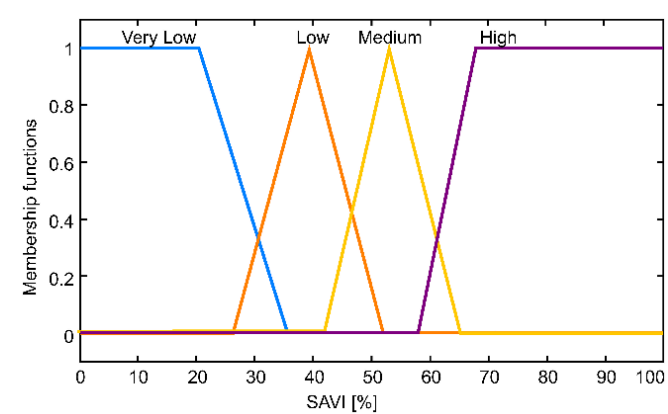

b)

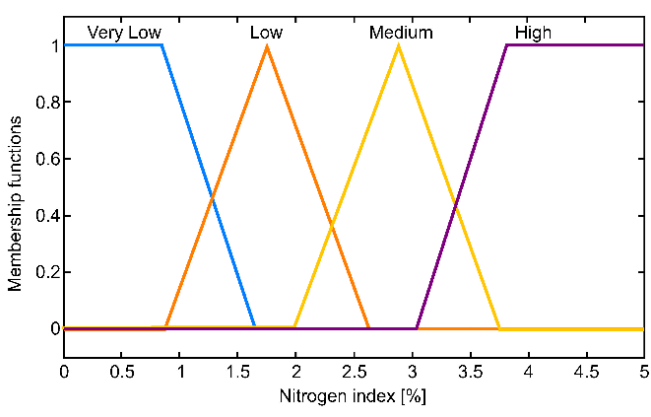

d)

Figure 2. Fuzzy set for canopy temperature (a), for soil-adjusted vegetation index (b), for surface soil moisture and for nitrogen index $(\mathrm{d})$

There were $192 \mathrm{f}$ rules to create after making system adjustments and reducing the number of linguistic variables. Thus, making these adjustments manually was time-consuming. A similar Fuzzification approach has been applied for input variables of the other experiment (Brule, Nebraska, United States) and provided in supplement material.

2.3.1.2. Fuzzification of output variables: control of speed and degree of opening of the solenoid valves in the sprinklers

We do not discuss the output variables because the sprinkler design is complex and not within the scope of this study. This procedure was replaced with a simpler approach developed jointly with the engineering team from Fockink (https://www.fockink.ind.br/\#), a center pivot manufacturer in Brazil. This company did not provide information regarding the project but provided relevant information to simplify data 
comparison. In this case, the pivot had no valve controller, and the Brazilian manufacturer does not commercialize center pivots with valve controller.

Center pivot speed is measured in percentage, this means that at maximum speed, the motor of the last tower moves continuously, and at $50 \%$ of the maximum speed, the delay time of the motor is equal to the corresponding movement time. The longer the center pivot takes to complete a full turn, the greater the depth reached by the water. Therefore, to increase the depth reached per cycle, the pivot rotation speed needs to decrease, and vice versa [50-51].

Given the lack of information in the literature regarding specific characteristics of what constitutes high or low speed, speed ranges were established based on expert knowledge for the pivots installed in the experimental area of the University of Nebraska (Figures 3). The fuzzy outputs for commercial farm in Mato Grosso, see in the supplement information.

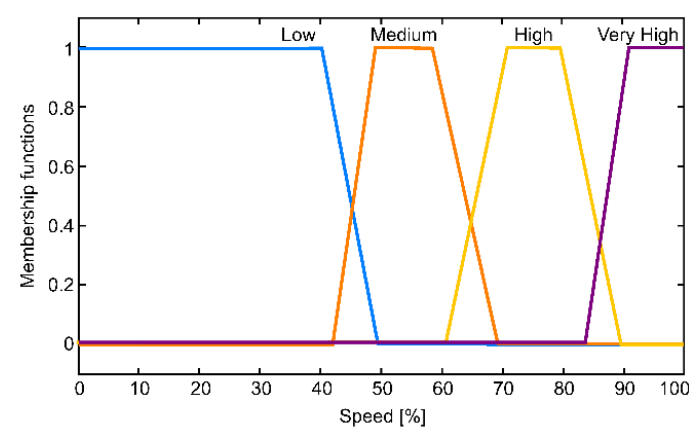

a)

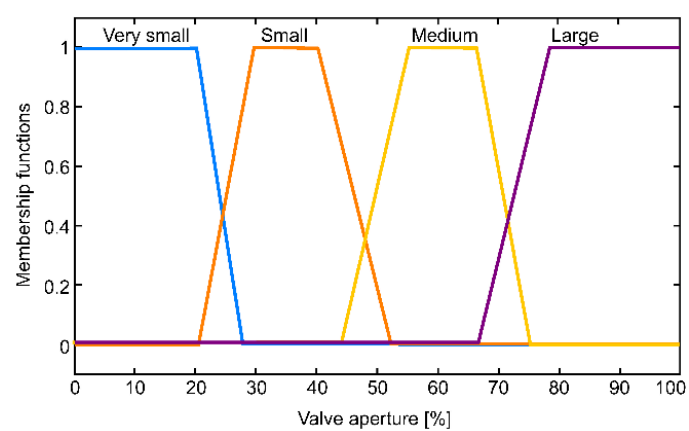

b)

Figure 3. a) Fuzzy output set for the rotation speed; b) Fuzzy output set for valves of the center pivot installed in an experimental area of the University of Nebraska-Lincoln.

The following linguistic variables were selected given that speed variation was conditioned to a range from $0 \%$ to $100 \%$ : very high $(\mathrm{VH}), 90-100 \%$; high $(\mathrm{H}), 70-80 \%$; moderate $(\mathrm{M}), 50-60 \%$; and low $(\mathrm{L}), 0-40 \%$. These values were initially chosen based on information from expert knowledge as no information was found in the reviewed literature on this type of distribution of values. Pivots generally have valves with fixed openings, but variable openings have been used in more specific studies [15; 17] [52-58]. However, no study has before described approaches for controlling these valves, as we propose in this study.

Therefore, based on expert knowledge, we established ranges for the degree of opening of the sprinkler valves of the center pivots installed in the selected commercial farm in Mato Grosso and an experimental area of the University of Nebraska. Four linguistic variables were used: large (L), 90-100\%; medium (M), 60-80\%; small (S), 30-50\%; and very small (VS), $0-20 \%$. After tuning the fuzzy system, the differences between the fuzzy output sets for this parameter were significant for $\mathrm{L}, \mathrm{M}$, and $\mathrm{S}$. These differences impacted the water volume to be used for irrigation.

\subsubsection{Rule Base}

A fuzzy rule is a simple if-then rule with one condition and one conclusion. Therefore, fuzzy rules assume the form: if $\mathrm{x}$ is $\mathrm{A}$, then $\mathrm{y}$ is $\mathrm{B}$, where $\mathrm{A}$ and $\mathrm{B}$ are linguistic values defined by fuzzy sets at the intervals (universe of discourse) $X$ and $Y$, respectively. The 
"if" part of the " $\mathrm{x}$ is $\mathrm{A}$ " rule is called the antecedent or premise, whereas the "then" part of the " $y$ is B" rule is designated the consequent or conclusion. An auxiliary tool developed by experts for constructing the 192 rules is shown in Table 4.

Table 4. Effect of input variables on the control of speed and valves.

\begin{tabular}{|c|c|c|c|c|c|c|c|c|c|}
\hline \multicolumn{2}{|c|}{ Input variables } & \multicolumn{4}{|c|}{ Effect on center pivot speed } & \multicolumn{4}{|c|}{$\begin{array}{c}\text { Effect on opening of center pivot } \\
\text { valves }\end{array}$} \\
\hline & & Low & Moderate & High & $\begin{array}{l}\text { Very } \\
\text { high }\end{array}$ & Small & Medium & Large & $\begin{array}{l}\text { Very } \\
\text { large }\end{array}$ \\
\hline \multirow{4}{*}{$\begin{array}{l}\text { Nitrogen in- } \\
\quad \operatorname{dex}[\%]\end{array}$} & Very low & & & $X$ & & $X$ & & & \\
\hline & Low & & & $x$ & & $X$ & & & \\
\hline & Medium & & $x$ & & & & $X$ & & \\
\hline & High & $X$ & & & & & & $X$ & \\
\hline \multirow{4}{*}{$\begin{array}{c}\text { Soil-ad- } \\
\text { justed vege- } \\
\text { tation index } \\
{[\%]}\end{array}$} & Very low & $X$ & & & & & & & $X$ \\
\hline & Low & $X$ & & & & & & $X$ & \\
\hline & Medium & & $X$ & & & & $X$ & & \\
\hline & High & & & $x$ & & & $x$ & & \\
\hline \multirow{4}{*}{$\begin{array}{c}\text { Surface soil } \\
\text { moisture } \\
{[\%]}\end{array}$} & Very low & $X$ & & & & & & & $X$ \\
\hline & Low & $X$ & & & & & & $X$ & \\
\hline & Medium & & $X$ & & & & $X$ & & \\
\hline & High & & & & $X$ & $X$ & & & \\
\hline \multirow{3}{*}{$\begin{array}{c}\text { Canopy } \\
\text { temperature } \\
{\left[{ }^{\circ} \mathrm{C}\right]}\end{array}$} & Low & & & & $X$ & $X$ & & & \\
\hline & Normal & & $X$ & & & & $X$ & & \\
\hline & High & $X$ & & & & & & & $X$ \\
\hline
\end{tabular}

The proposed fuzzy system is multivariable, and both the antecedent and consequent have several components. Although there are several strategies to build this type of system [37] [59-60]. The rules were created according to the effect (Table 4) of each input variable on water stress; the building elements of the center pivot were also considered. The application rules did not change in both study sites, and the same rule base was used in the proposed fuzzy system.

\subsubsection{Fuzzy Inference}

A Mamdani method [45] was chosen for the inference engine (Figure 4) because it is simpler and more intuitive than the Takagi-Sugeno-Kang inference method [61-62]. In addition, Mamdani models are commonly used in studies related to irrigation systems [24; 34] [63-65]. The logical connector "and" modeled by t-norm $\wedge$ (minimum) was used in this present study. 


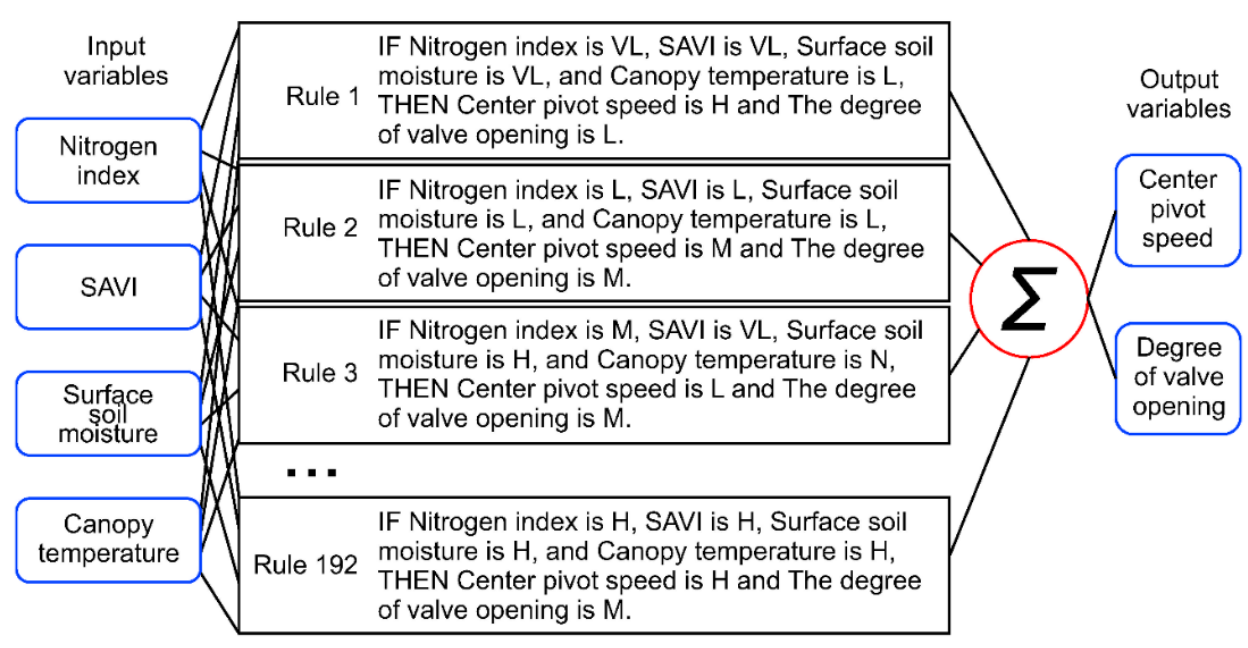

Figure 4. Mamdani System for fuzzy-VRI.

The following steps are required to build a fuzzy system with a Mamdani method: (1) crisp inputs are converted into fuzzy inputs using MFs, (2) the necessary fuzzy rules are created, (3) a rule-based inference is determined, (4) the rule consequent is determined by combining the power of the rule with the MF output, (5) all consequents are combined to obtain the output distribution, and (6) the output distribution is defuzzified.

Mapping provides the basis for making decisions and identifying patterns. In Mamdani models, MF outputs are also fuzzy sets. After each if-then rule that generates a modified fuzzy set as output, the aggregation method is used to combine the fuzzy sets that represent the outputs of the rules into a single fuzzy set to make decisions. The final combined fuzzy set is the output of the aggregation process, and each output variable of the FIS has a corresponding combined fuzzy set for reference [66].

\subsubsection{Defuzzification}

The output generated in Mamdani models is a fuzzy subset. Furthermore, the actual value represented by this output needs to be indicated. The final step in the fuzzy inference is defuzzification, whereby the combined fuzzy set of the aggregation process produces a single scalar quantity. As the name implies, defuzzification is the opposite of fuzzification and assigns a crisp amount from the fuzzy set range to the output variable. Among the many defuzzification methods described in the literature, the centroid method (also known as the center of area or center of gravity) is the most widely used [46]. The centroid of the area generated by the combination of all rules is calculated using Equation $(1)$

$$
\mu^{*}=\frac{\sum_{j=1}^{N} \mu_{i} \times \mu_{\text {out }}\left(\mu_{i}\right)}{\sum_{j=1}^{N} \mu_{\text {out }}\left(\mu_{i}\right)}
$$

where $\mu_{\text {out }}\left(u_{i}\right)$ is the area of an MF modified by the result of the fuzzy inference, and $u_{i}$ is the centroid of the MF.

\section{Results}




\subsection{Results for the Commercial Farm}

Based on the irrigation dates provided by Irriga ${ }^{\circledR}$ System and the satellite overpass (Table 1), it was possible to create a complete dataset to test the developed Fuzzy-VRI approach. By combining and analyzing both data (satellite and irrigation), four events are identified. In the first event, four out of eight dates in which satellite data were acquired coincided with dates in which irrigation was scheduled to start. In the second event, remote sensing data were acquired on the day before the beginning of irrigation. In the third event (July 5), data were acquired on the day following the end of irrigation. In the fourth event, data were acquired on the last day of irrigation.

\subsubsection{Results for June 17, 2018}

To illustrate the potential variability in the fuzzy-VRI output in different zones, $30^{\circ}$ divisions are shown in Figure 5. The results should be interpreted as follows: the analysis began in quadrant I and ended in quadrant IV, with a counterclockwise direction. For the analysis of the June 17, 2018 event, it should be noted that this was also the scheduled date for the actual irrigation provided by the Irriga ${ }^{\circledR}$ system. The results for this date showed that the speed ranged from $77 \%$ to $90 \%$ (Figure $5 b$ ).

(a)

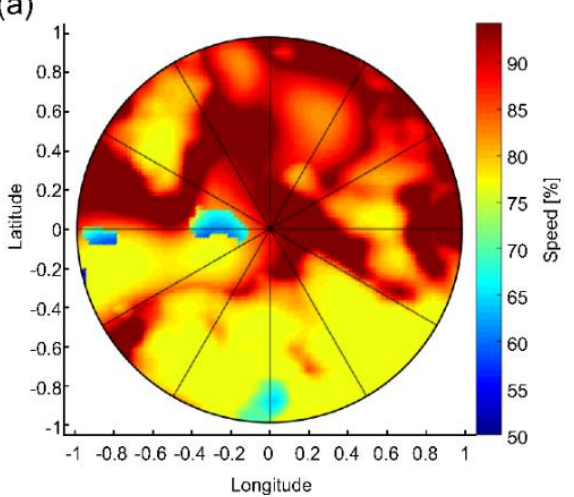

(b)

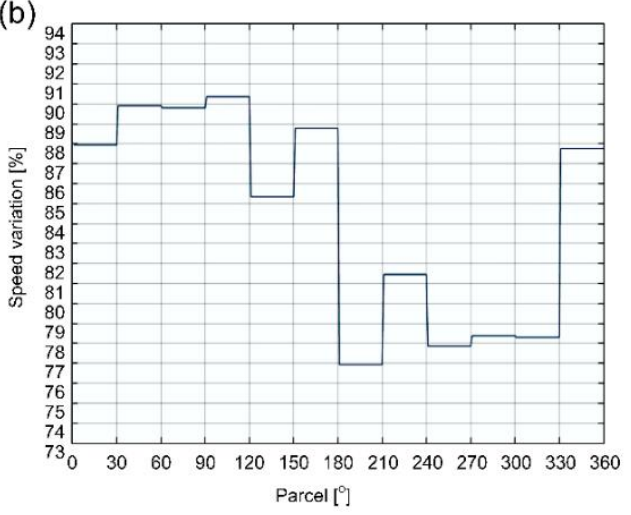

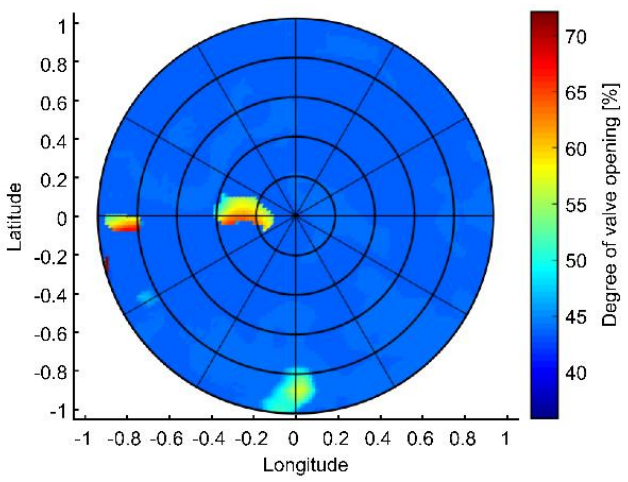

Figure 5. a) Rotation speed of the center pivot; b) Average rotation speed in each parcel, and c) Degree of solenoid valve opening

The speed of the center pivots varied, resulting in different irrigation depths. Two distinct zones were detected: one in the upper semicircle $\left(0^{\circ}\right.$ to $\left.180^{\circ}\right)$ where the estimated speed was close to $90 \%$, and another in the lower semicircle $\left(180^{\circ}\right.$ to $\left.360^{\circ}\right)$ where the speed decreased to an average of 77\%. The proposed methodology for the fuzzy-VRI depends partly on the number of chosen parcels and MZs given that assigning of setpoints or percentages is based on the average value in each parcel. 
The crop area was divided radially into five zones, from the center $(Z 1)$ to the edge (Z5) (Figure 5-c). Note that with this division, the small spots detected were contained within parcel 6 (between radial zones 1 and 2), parcel 7 (radial zone 5), and one region between parcels 9 and 10 (radial zone 5).

There was a weak distinction between the areas and higher uniformity in the distribution of the valve control. This lack of sensitivity may be attributed to the small number of inputs because some variables may better indicate spatial variability. The control of valve opening in each zone is shown in Figure 6.
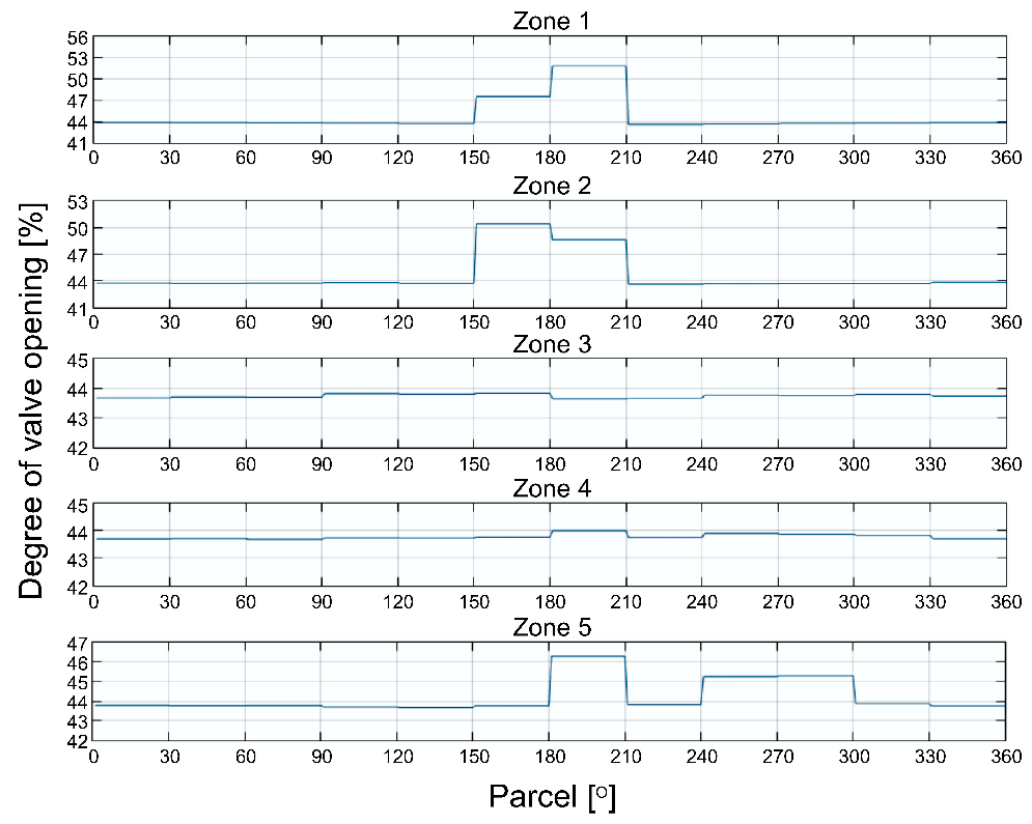

Figure 6. Degree of solenoid valve opening in each management zone.

The same zones displayed in Figure 5 are shown in Figure 6. Given that valve control is based on the average estimates provided by the fuzzy system, there was no significant variation in zones 3 and 4 . To compare the actual irrigation system in use with the setpoint estimates for speed and valve opening control generated by the fuzzy-VRI, the setpoints should be associated with a pivot construction specification.

The results obtained when speed and valve opening setpoints were sent to a pivot adjusted to irrigate at a depth of $9 \mathrm{~mm}$ are shown in Figure 7. The average depth was 5 $\mathrm{mm}$, with some zones indicating less penetration than determined by the irrigation management company. 


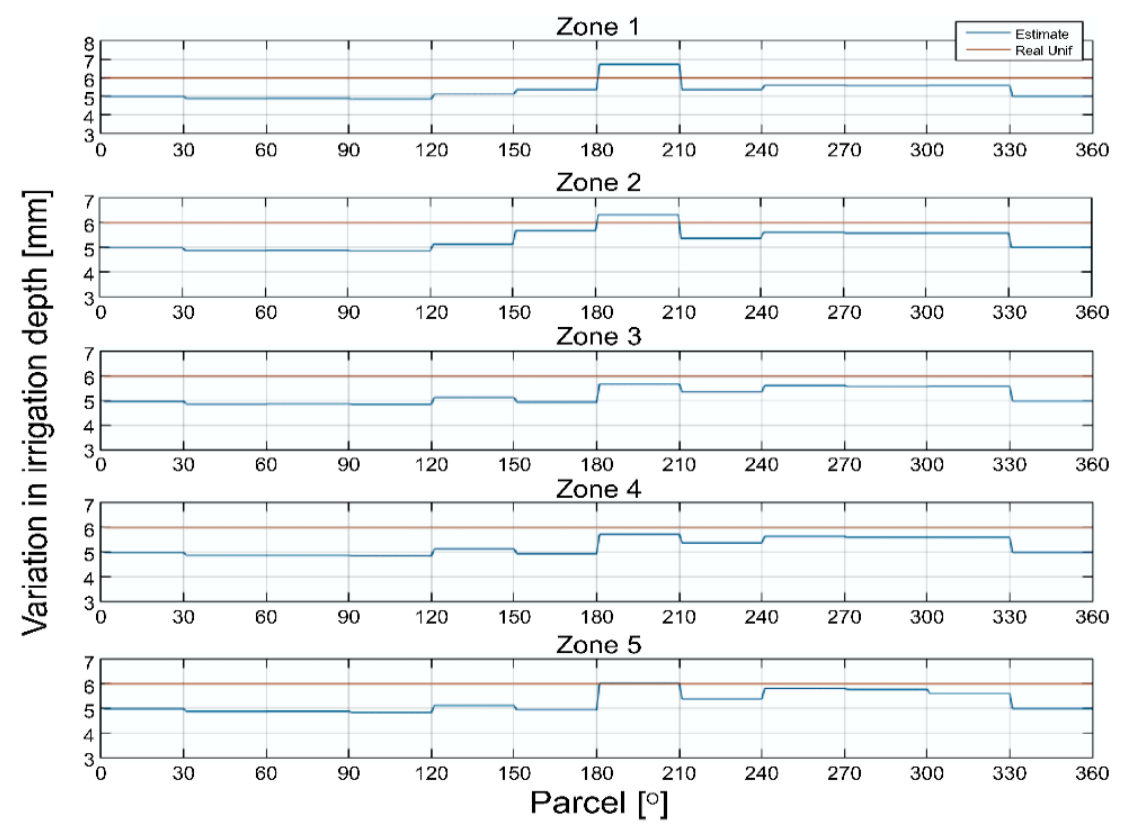

Figure 7. Estimated irrigation depth for each management zone.

\subsubsection{Results for June 27,2018}

The remote sensing data analyzed by the FIS indicated variations in speed (Figure 8). It is worth highlighting that the study area was partitioned manually, and the best division to separate the MZs was achieved with $20^{\circ}$ parcels. The analysis of the valve opening control, as signaled by the setpoint, showed that the system could recommend VRI practices with a significant range in degree of valve opening (Figure 8c). Furthermore, the center of the study area required more water. Therefore, increasing the number of parcels in each area might increase the coverage of MZs based on the VRI criteria.
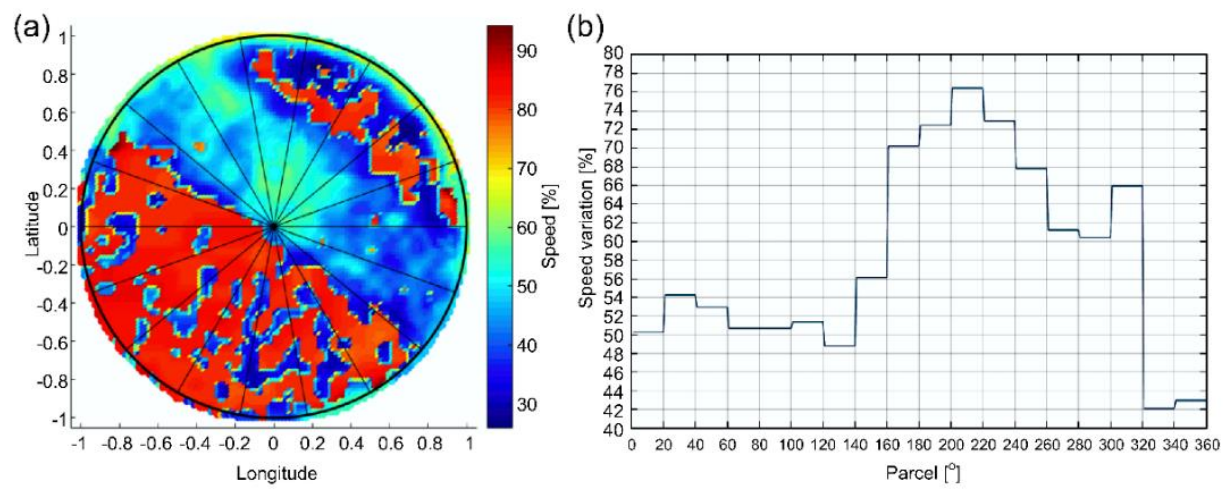


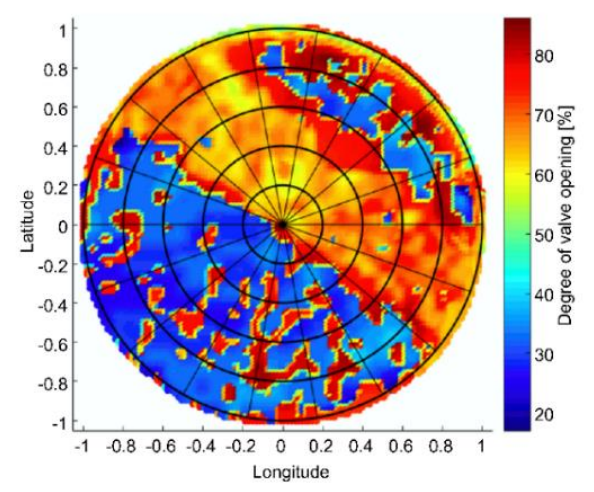

Figure 8. a) Rotation speed of the center pivot; b) Average rotation speed in each parcel; c) Degree of solenoid valve opening.

The same area was analyzed again after 10 days, and actual irrigation was performed according to the schedule shown in Table 3. The satellite data coincided with the date of a scheduled irrigation, which had an actual irrigation depth of $6.1 \mathrm{~mm}$. There was a welldelimited area from parcel $17\left(320^{\circ}\right)$ to parcel $7\left(120^{\circ}\right)$ characterized by low speed and another area (red) characterized by high speed. That the speed varied from $42 \%$ to $76 \%$, demonstrating that the fuzzy-VRI detected a range of crop conditions, indicating zones with different irrigation requirements.

There was significant variability in the degree of valve opening in the MZs (shown in orange) located in the lower semicircle. Although there was no information on potential problems in these zones in the field, the fuzzy-VRI was sensitive to input data and detected spatial variability. The significant variability in the degree of valve opening in all five zones indicates that there are considerable differences in the water volume to be applied.

Therefore, upon receiving the setpoint signals the CPIS applies a water volume close to that estimated by the water balance method adopted by the partner company. Figure 9 indicates that the recommended irrigation volume was overestimated in some regions and close to the applied volumes in other regions. Despite this variation, the system fulfilled its objective by recommending spatially variable irrigation.
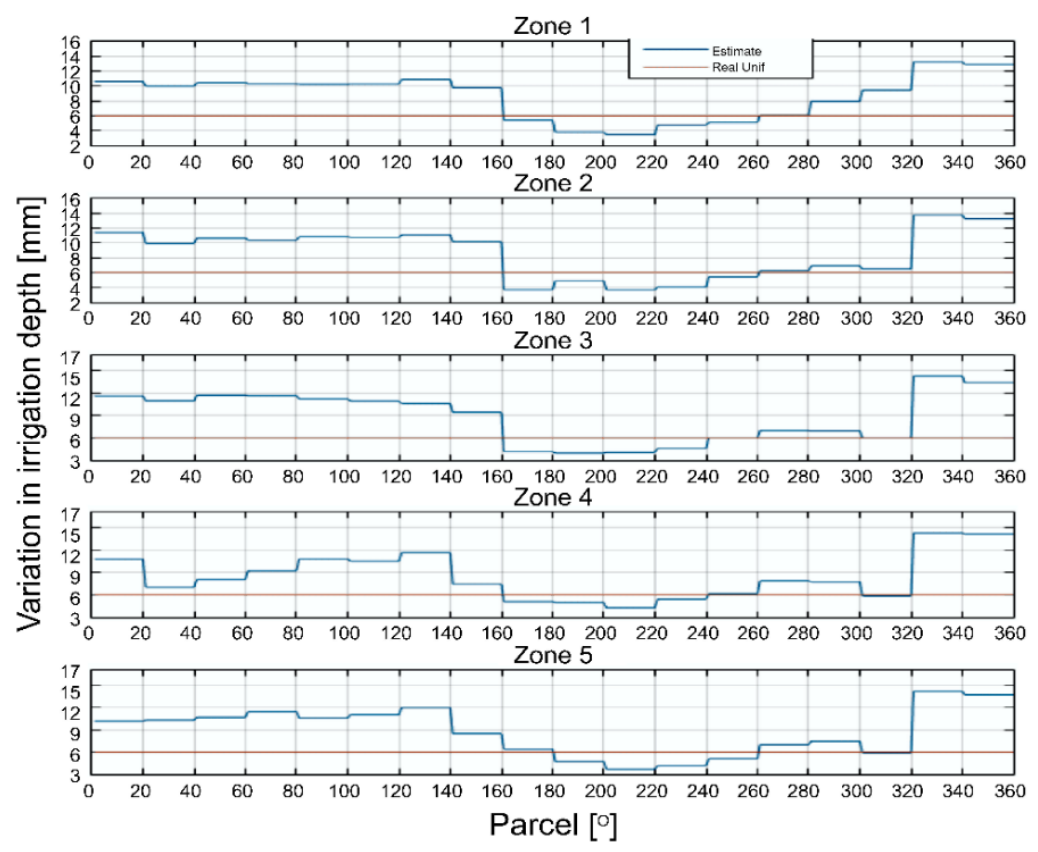
Figure 9. Estimated irrigation depth for each management zone.

Although the FIS did not have the best variables for analyzing water stress in crops, the inferred values were close to those determined by Irriga System. However, the water depth setpoint values were twice the actual values in some regions. The reason for this difference is unknown but may be related to the lack of an input variable that indicates the SSM or a normalization variable of the environmental conditions on a specific date. The latter hypothesis will be discussed more in the experimental area in Brule, United States.

\subsubsection{Results for August 27, 2018}

The last irrigation event was performed in the study area on August 28, 2018. However, the i-ekbase system only provided the images from August 27, 2018, i.e., data were analyzed one day before actual irrigation. It is expected that the FIS indicates the speed and degree of the valve opening based on the amount of water required to replace water losses on that date. The results obtained using a conventional method can be compared with the inferred values.

The estimated pivot speed was relatively lower on this date than on previous dates, which might suggest a higher irrigation volume. The region located in quadrant IV in a previous analysis is highlighted in Figure 10a.

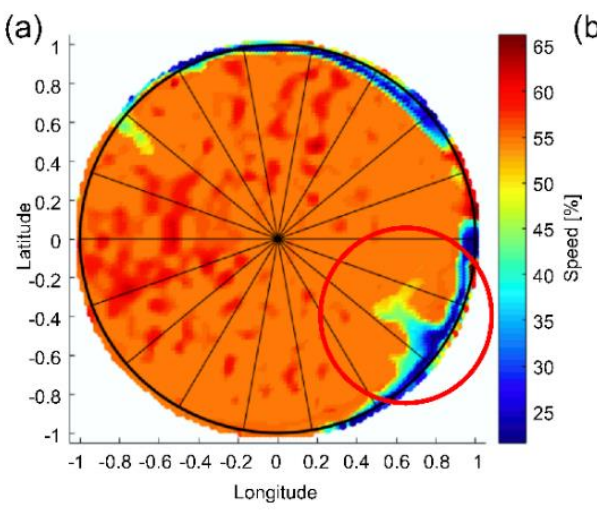

(b)
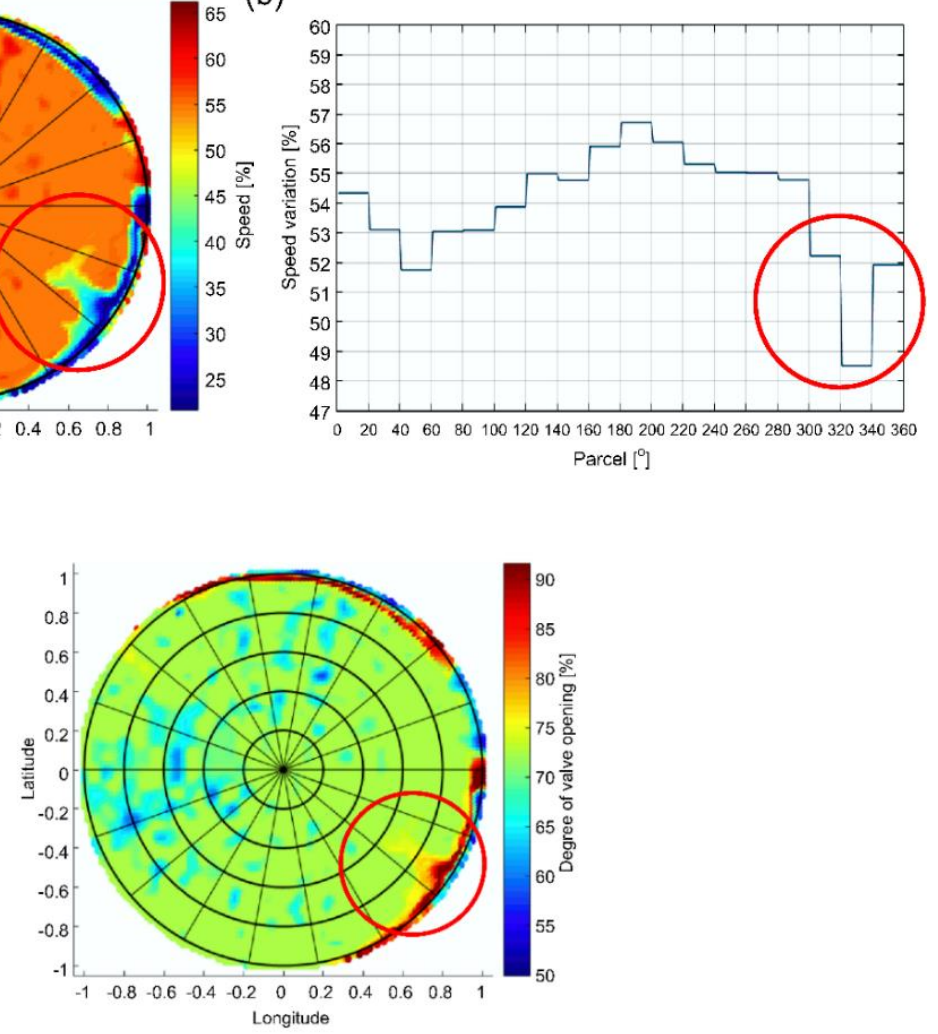

Figure 10. a) Rotation speed of the center pivot; b) Average rotation speed in each parcel; c) Degree of solenoid valve opening

The FIS had sufficient sensitivity to predict possible problems in the cultivated areas. However, there was no additional information to corroborate this hypothesis, and the irrigation management company did not report problems in this study area. Therefore, this problem was treated as a variation in water requirements, as was the case in other studies. 
The output signals for the valve opening (Figure 10c) had a uniform spatial distribution and indicated that the zones with lower variability in the speed of the center pivot had a higher irrigation requirement.

It is worth noting that the characteristics of zone 1 from all study sites were not relevant for this analysis because these regions were not cultivated. However, the results are presented for analytical purposes. Spatial variability in the valve opening was absent in zone 1 and high in zone 5 (located at $320^{\circ}-340^{\circ}$ ) according to estimations from the fuzzyVRI system. Spatial variability in speed control was similar in the valve opening. The variability in zone 5 was significantly higher than that in the other zones. The values reached approximately $73 \%$ of the maximum in zones $1-4$ and $79 \%$ of the maximum in zone 5 , indicating that the proposed FIS detected spatially distributed regions, potentially with different irrigation requirements.

To confirm the sensitivity of the fuzzy-VRI in estimating irrigation requirements, the comparison between the actual irrigation volumes applied by a conventional uniform system and those estimated by the FIS is shown in Figure 11.

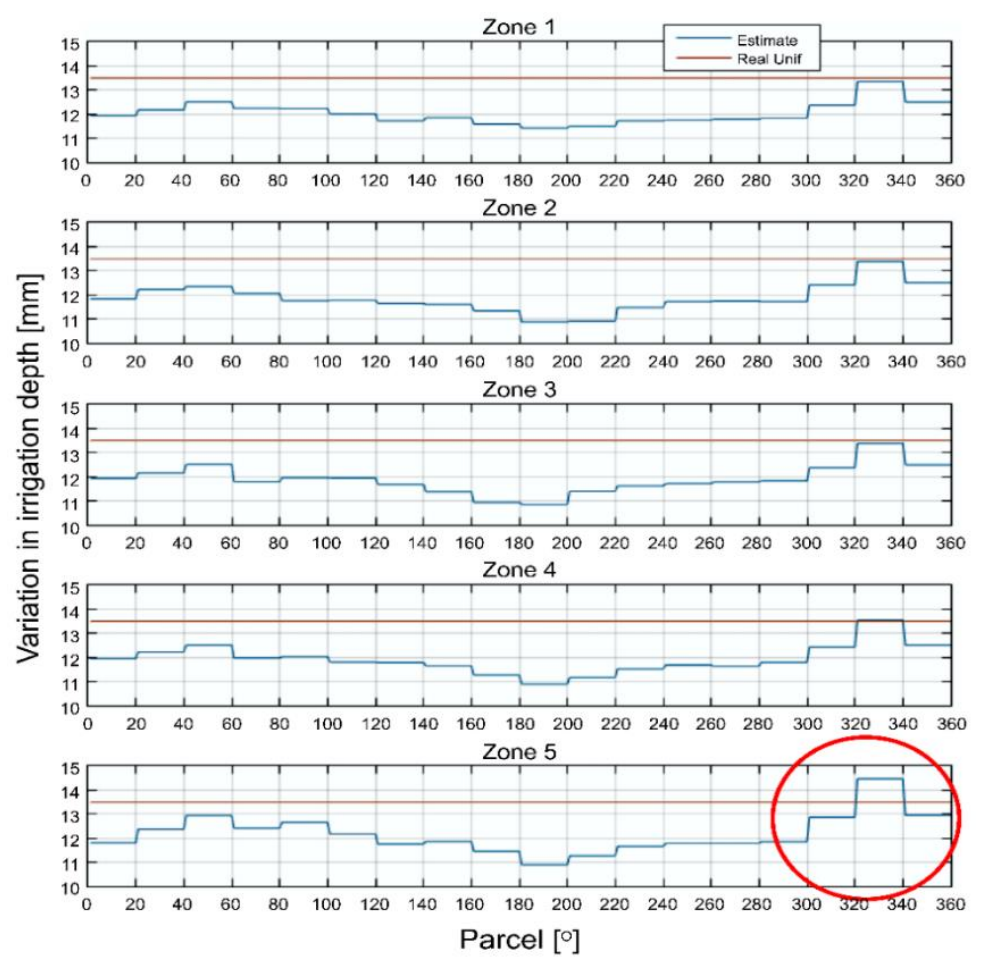

Figure 11. Estimated irrigation depth for each management zone.

The region located at $320^{\circ}-340^{\circ}$ in zone 5 was considered an attention zone (irrigation is highly recommended), and the estimated irrigation depth was smaller than the applied volume, demonstrating that the system could monitor the water requirements of crops over time. Therefore, it is safe to claim that the fuzzy-VRI could infer spatial and temporal variability in irrigation volumes.

\subsection{Results for the Experimental Area in Brule, Nebraska, United States}

The fuzzy-VRI system analyzed the dates of four irrigation events (events that started one day after satellite image data acquisition and ended the following day). June 24, 2016, which was the date provided by i-ekbase, corresponded to the day following the irrigation event on June 23, for which the full turn was completed by the CPIS on June 25. Also analyzed remote sensing data on the day after the irrigation event and made inferences 
on the day before the start of irrigation. July 26, 2016 was the last day of the irrigation event. These samples were used to determine the degree of sensitivity of the proposed system.

\subsubsection{Results for June 24, 2016}

The intelligent system determined the variation in center pivot speed (Figure 12) and the degree of opening of the sprinklers' solenoid valve (Figure 12c). Pivot rotation speed varied widely between regions (from $46 \%$ to $59 \%$ of the maximum speed the pivot could reach), and it was higher in the regions shown in red and lower in the regions shown in blue. This result corresponds to reference values, which should be sent to the center pivot controller to evaluate the percentage rotation speed.
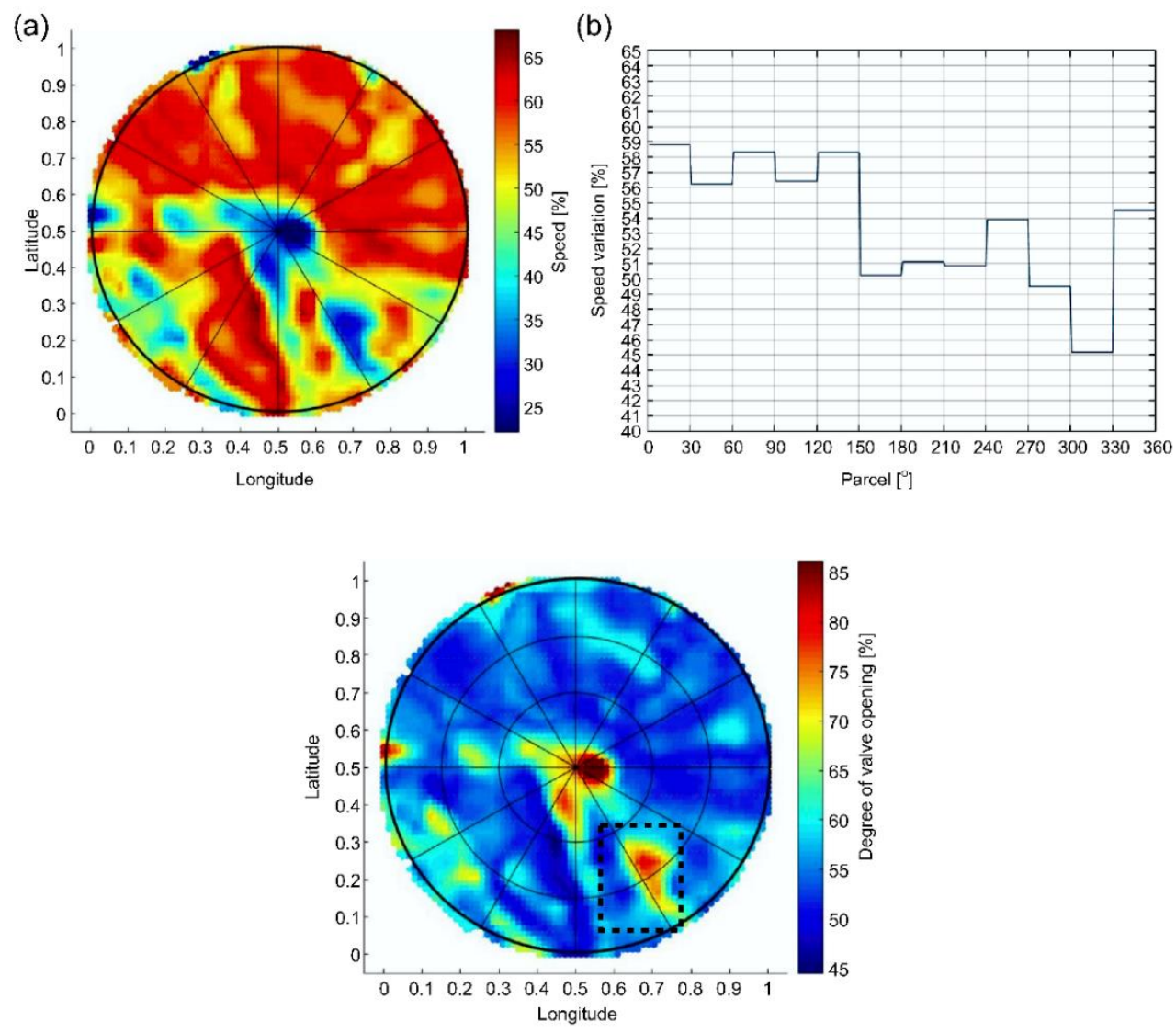

Figure 12. a) Rotation speed of the center pivot; b) Average rotation speed in each parcel; c) Degree of solenoid valve opening

The fuzzy-VRI system estimates the speed for each pixel. However, this information cannot be sent to the controller because the pivot has truss rods that move at the same speed as the center pipe. Hence, the speed data from each parcel were averaged and sent to the controller. This methodology is not available in the literature.

Valve openings varied by parcel in each zone $(1-3)$ (Figure 12c). The regions shown in red had a higher degree of opening, whereas the regions shown in blue had a lower degree of opening. The colors changed in the controls because the higher the speed, the lower was the irrigation volume, whereas the higher the degree of valve opening, the higher was the amount of water used for irrigation.

The center pivot regulated speed and valve opening according to the signals sent by the intelligent CPIS and applied the required water volume. The irrigation depth setpoints depend on the construction or specifications of the pivot (Figure 13). The chosen sprinkler 
size had an application depth of $15 \mathrm{~mm}$, i.e., if the solenoid valve received the signal to open completely and the rotation speed was set to $100 \%$, the pivot would apply a water depth of $15 \mathrm{~mm}$ in that zone.

The irrigation depths measured in [17] were identified as uniform irrigation distribution or remote sensing-based VRI (VRI-RS). The latter uses remote sensing and water balance measurements, whereas the former uses a neutron probe to measure SSM [67]. There was spatial variability in irrigation depths estimated indirectly by the fuzzy-VRI between the MZs.

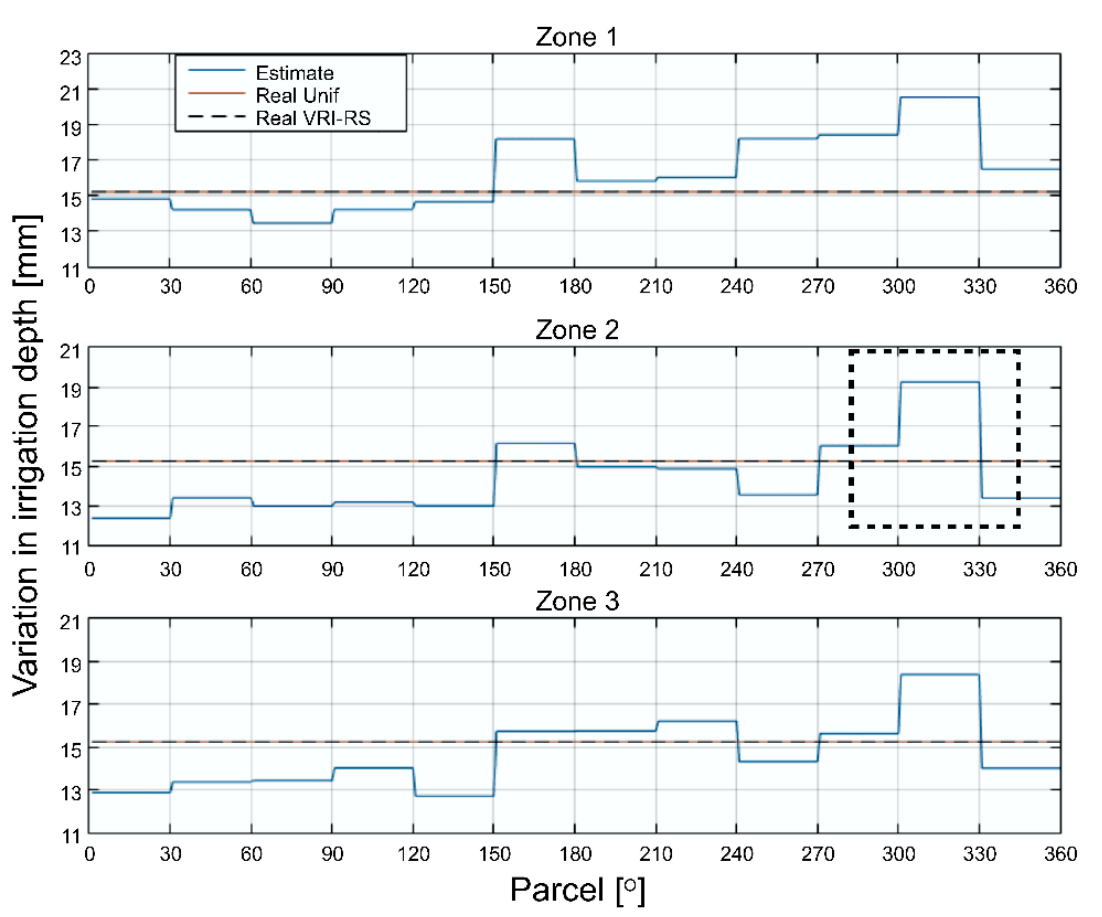

Figure 13. Estimated irrigation depth in each management zone.

At an angle of $300^{\circ}-360^{\circ}$ in MZ-2, the estimated volume was approximately $23 \%$ higher than that in Barker's study, indicating that this region had a higher water requirement. On this date, there were regions already irrigated by the CPIS (pointed out by the fuzzy-VRI for parcels between $0^{\circ}$ and $120^{\circ}$ ) and regions that were not yet irrigated (between $150^{\circ}$ and $360^{\circ}$ ), confirming that the proposed system distinguished between regions with different irrigation requirements.

The fuzzy-VRI system obtained the best results in the zone located between $300^{\circ}$ and $330^{\circ}$ (Figures $12-13$ ), and the water volume was different from that estimated by the neutron probe and VRI-RS model. This region was detected by the FIS and might have water deficit problems that should be addressed. The VRI model proposed by [17] did not accurately detect regions with a greater need for irrigation. In contrast, the analyzed FIS detected spatial variability in water requirement, and the estimated values were close to those found by the neutron probe, which is the standard equipment used for measuring water requirement in crops.

These results show that poorly managed agricultural practices can waste water and required irrigation volume depends on the type of crop. The amount of water consumed in this area is also linked to the type of crop, and it is worth noting that different plants require different amounts of water. The characteristics of the experimental area were different from those of commercial areas. The discussion on irrigation efficiency did not apply because this study area was experimental. 


\subsubsection{Results for September 12, 2016}

Given the limitations in the number of analyzed dates, there was a 24-day difference between September 12, 2016 and previous dates (August 19, 2016). September 12, 2016 was a special case for which it was concluded that the FIS needed a local input variable to balance the other input variables (offset measurement). The results of speed control from the fuzzy-VRI system are shown in Figure 14a. Two outputs in the fuzzy-VRI system mutually interfered with the irrigation volume. Hence, the valve opening setpoints were evaluated (Figure 14c).

The same critical MZs detected on the other dates were found on September 12. There was a $28 \%$ decrease in speed in the zone located between $240^{\circ}$ and $270^{\circ}$, indicating that this zone had a higher demand for irrigation.

(a)

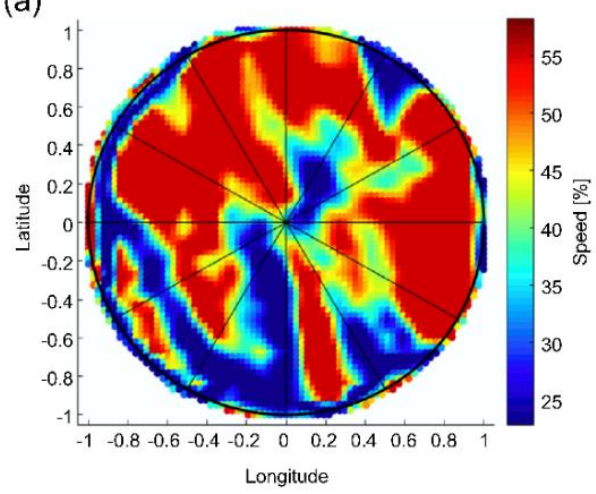

(b)

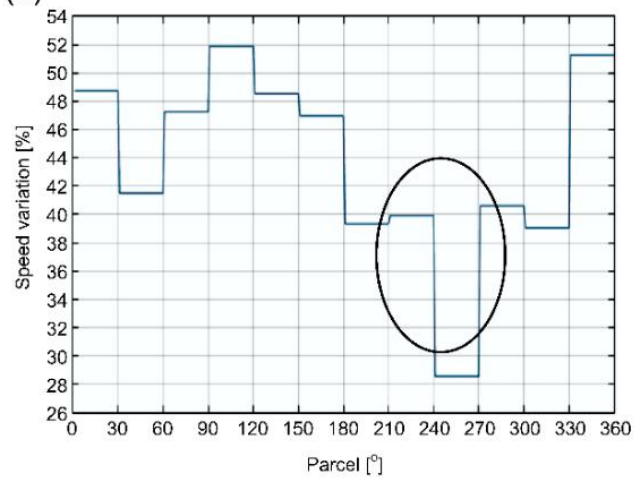

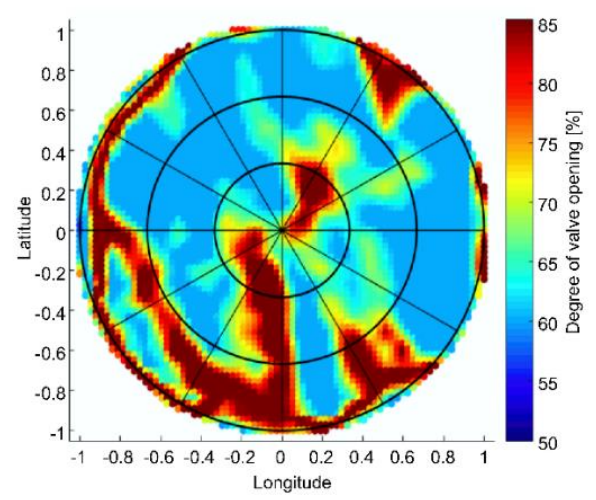

Figure 14. a) Rotation speed of the center pivot; b) Rotation speed in each parcel; c) Degree of solenoid valve opening

The analysis by the FIS showed that one zone presented a water deficit. Valve opening increased in the zone located between $240^{\circ}$ and $270^{\circ}$, confirming the trend for higher irrigation requirements (Figure 14c). The values estimated by the proposed system were similar to those estimated by the VRI-RS model, confirming that the system tuning (and possibly these input variables) was unbalanced and made the FIS as insensitive as the model proposed by [17].

The center pivot regulated speed and valve opening according to the signals sent by the intelligent CPIS and applied the required water volume. The irrigation depth setpoints depend on the construction or specifications of the pivot (Figure 15). 


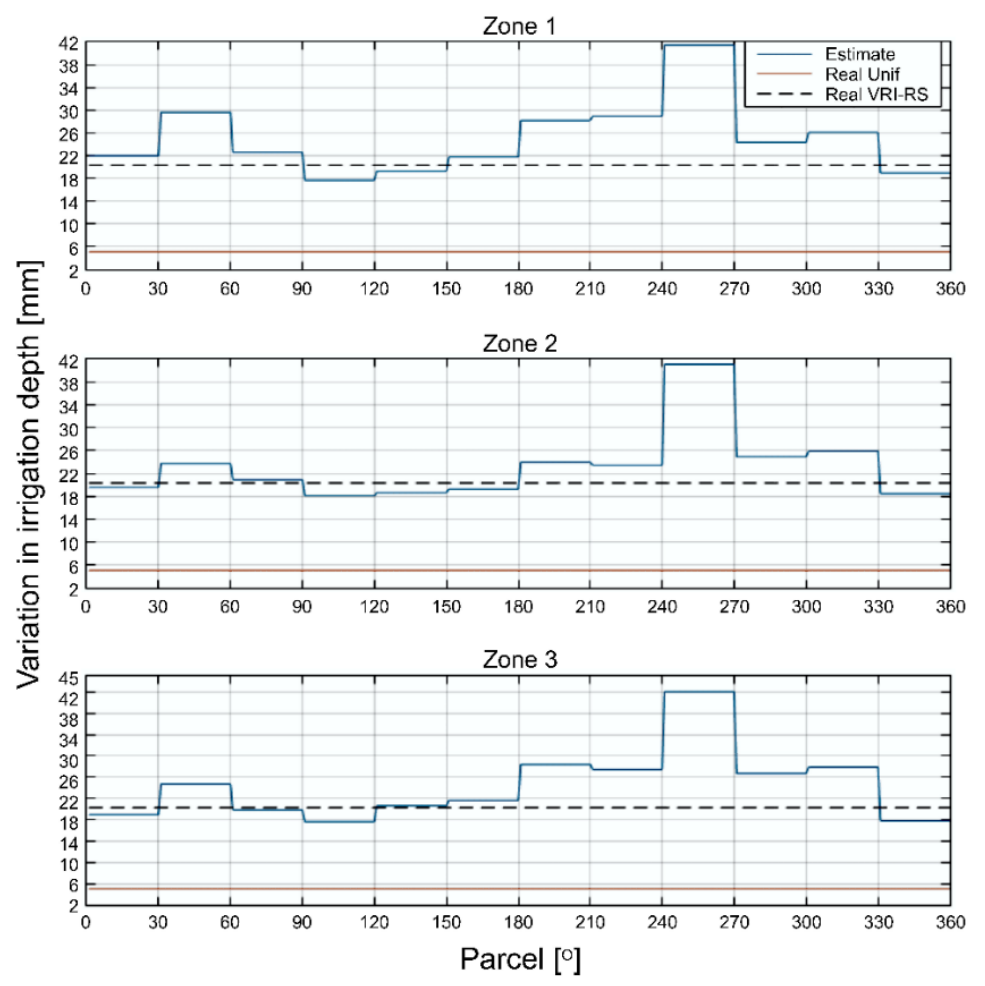

Figure 15. Estimated irrigation depth in each management zone.

Therefore, to confirm the hypothesis that the proposed system required local input variables to balance remote sensing input variables, the FIS was adjusted only for this date. It is worth highlighting that the same manually-tuned system was used on all dates without further adjustments. The use of fuzzy logic was proposed to enable the new precision irrigation system interpret ambiguous, vague, or inaccurate environmental data. Therefore, it was not necessary to perform manual adjustments to balance input variables on all dates or create a FIS for each date. September 12 was an exception. The original MF parameters and the new manually-adjusted parameters are shown in Table 6.

Table 6. Changes in membership function parameters.

\begin{tabular}{|c|c|c|c|c|c|c|c|c|c|}
\hline \multirow{4}{*}{$\begin{array}{l}\text { Input varia- } \\
\text { bles }\end{array}$} & \multicolumn{4}{|c|}{ Original fuzzy system } & \multicolumn{5}{|c|}{ Modified fuzzy system } \\
\hline & \multicolumn{4}{|c|}{ Triangular function } & \multicolumn{5}{|c|}{$\begin{array}{c}\text { Triangular and trapezoidal func- } \\
\text { tions }\end{array}$} \\
\hline & \multirow[t]{2}{*}{$\begin{array}{l}\text { Linguistic } \\
\text { variables }\end{array}$} & \multicolumn{3}{|c|}{ Vertices } & \multirow[t]{2}{*}{$\begin{array}{l}\text { Linguistic } \\
\text { variables }\end{array}$} & \multicolumn{4}{|c|}{ Vertices } \\
\hline & & $\mathrm{a}$ & $\mathrm{b}$ & $\mathrm{c}$ & & $\mathrm{a}$ & $\mathrm{b}$ & $\mathrm{c}$ & $\mathrm{d}^{*}$ \\
\hline \multirow{3}{*}{ Temperature } & low & $\infty$ & 14 & 19 & low & $\infty$ & 16 & 20 & \\
\hline & normal & 14 & 20 & 25 & normal & 16 & 20 & 28 & 30 \\
\hline & high & 20 & 25 & $\infty$ & high & 28 & 30 & $\infty$ & \\
\hline \multirow{4}{*}{$\begin{array}{l}\text { Soil-adjusted } \\
\text { vegetation in- } \\
\text { dex }\end{array}$} & very low & $\infty$ & 15 & 30 & very low & $\infty$ & 15 & 30 & \\
\hline & low & 20 & 30 & 40 & low & 20 & 32 & 47 & \\
\hline & intermediate & 30 & 45 & 60 & intermediate & 36 & 52 & 68 & \\
\hline & high & 50 & 60 & $\infty$ & high & 60 & 70 & $\infty$ & \\
\hline \multirow{3}{*}{$\begin{array}{l}\text { Surface soil } \\
\text { moisture }\end{array}$} & very low & $\infty$ & 4 & 9 & very low & $\infty$ & 5 & 8 & \\
\hline & low & 4 & 11 & 17 & low & 5 & 11 & 15 & \\
\hline & intermediate & 13 & 20 & 26 & intermediate & 12 & 17 & 21 & \\
\hline
\end{tabular}




\begin{tabular}{|c|c|c|c|c|c|c|c|c|}
\hline & high & 21 & 28 & $\infty$ & high & 18 & 22 & $\infty$ \\
\hline \multirow{4}{*}{$\begin{array}{l}\text { Nitrogen in- } \\
\text { dex }\end{array}$} & very low & $\infty$ & 0.8 & 1.6 & very low & $\infty$ & 0.6 & 1.3 \\
\hline & low & 0.8 & 1.6 & 2.6 & low & 0.7 & 1.5 & 2.1 \\
\hline & intermediate & 2 & 3 & 3.7 & intermediate & 1.6 & 2.3 & 3 \\
\hline & high & 3 & 3.7 & $\infty$ & high & 2.5 & 3 & $\infty$ \\
\hline
\end{tabular}

The modified system did not change the number of MFs and MF outputs; hence, it did not introduce new rules. The proposed changes included tuning and changing the type of MF of the fuzzification step. Fine-tuning was based on the observations and analysis of remote sensing data. Moreover, the maximum, minimum, and average values of each variable were considered for this date only. This approach enabled making a smaller adjustment to the input variable that measured leaf development or SAVI. However, the adjustments carried out for CT, SSM, and NI were the most significant.

For $\mathrm{CT}$, the MFs and their parameters changed from a triangular to a trapezoidal function. Therefore, the inference of CT became less sensitive to small variations. Further, the temperature changed from high to normal, which changed the interpretation of the input variations and pushed the system to use the rules for this new temperature level. The range of values corresponding to a high SSM also changed, which made the system more sensitive to small increments in SSM. The same type of recalibration was performed for the NI variable, making the FIS more sensitive to detecting intermediate NI values.

Furthermore, the recalibrated fuzzy system was tested on the input data from September 12, 2016, and the result showed a decrease in the number of regions with variabilities and the existence of water deficit problems in regions near the border of zone 3 (Figure 16).

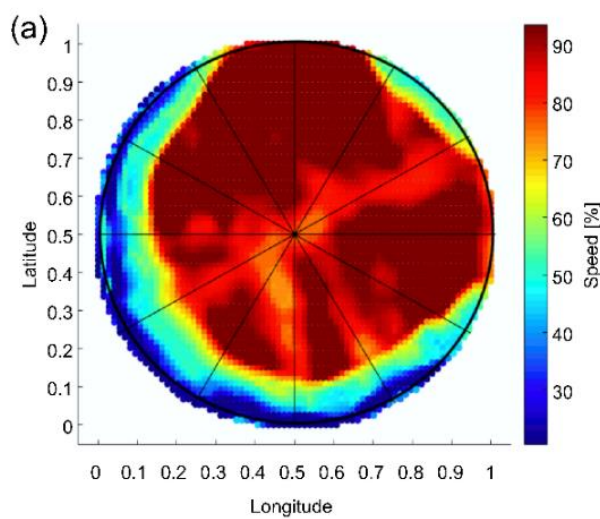

Longitude

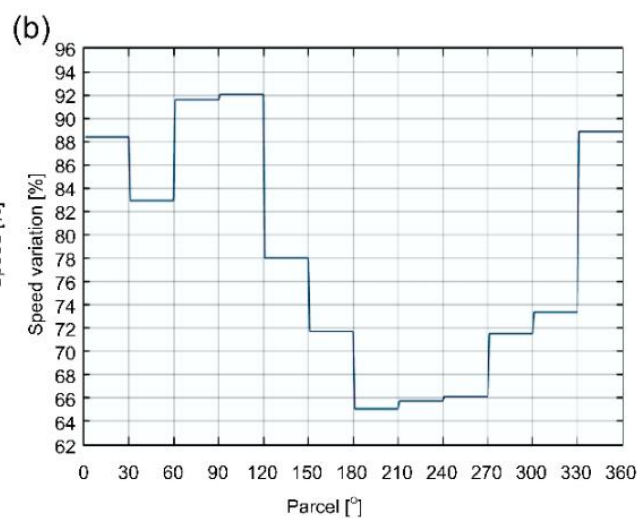

Parcel [ $\left[{ }^{\circ}\right.$

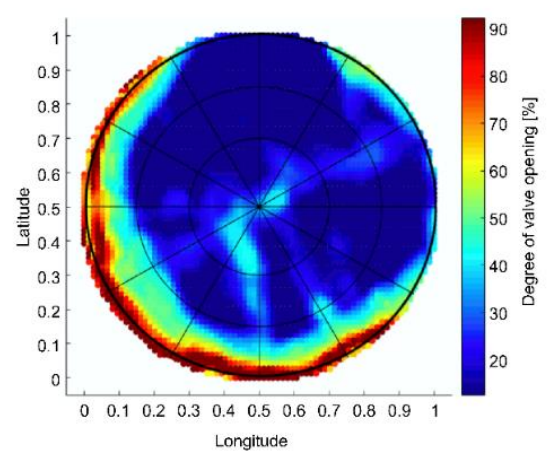

Figure 16. a) Rotation speed of the center pivot; b) Average rotation speed for each parcel; c) Degree of opening of solenoid valves. 
Another feature was that the speed was high, which had not been detected previously; maximum values ranged from $64 \%$ to $92 \%$, indicating that the irrigation volume was low. The number of regions with variations in valve control output also decreased (Figure 16c), demonstrating that the adjustments made the FIS less sensitive to temperature changes and more sensitive to changes in SSM. Despite confirming a slight increase in the degree of valve opening in zone 3 , the percentage value for this variable was not higher than $20 \%$, confirming that the water volume to be applied was low.

The analysis of the two output signals - speed and degree of sprinkler valve opening - showed that the irrigation volumes estimated by the fuzzy-VRI were low (Figure 17). The estimated values were close to those estimated by the neutron probe, demonstrating the sensitivity of calibrated FISs to irrigation depth measurement models. The choice of inputs that can faithfully represent local events is critical. In the proposed model, the adjustment in MFs for CT, SSM, and NI was decisive to infer that it was unnecessary to continue irrigating using the same amount of water.

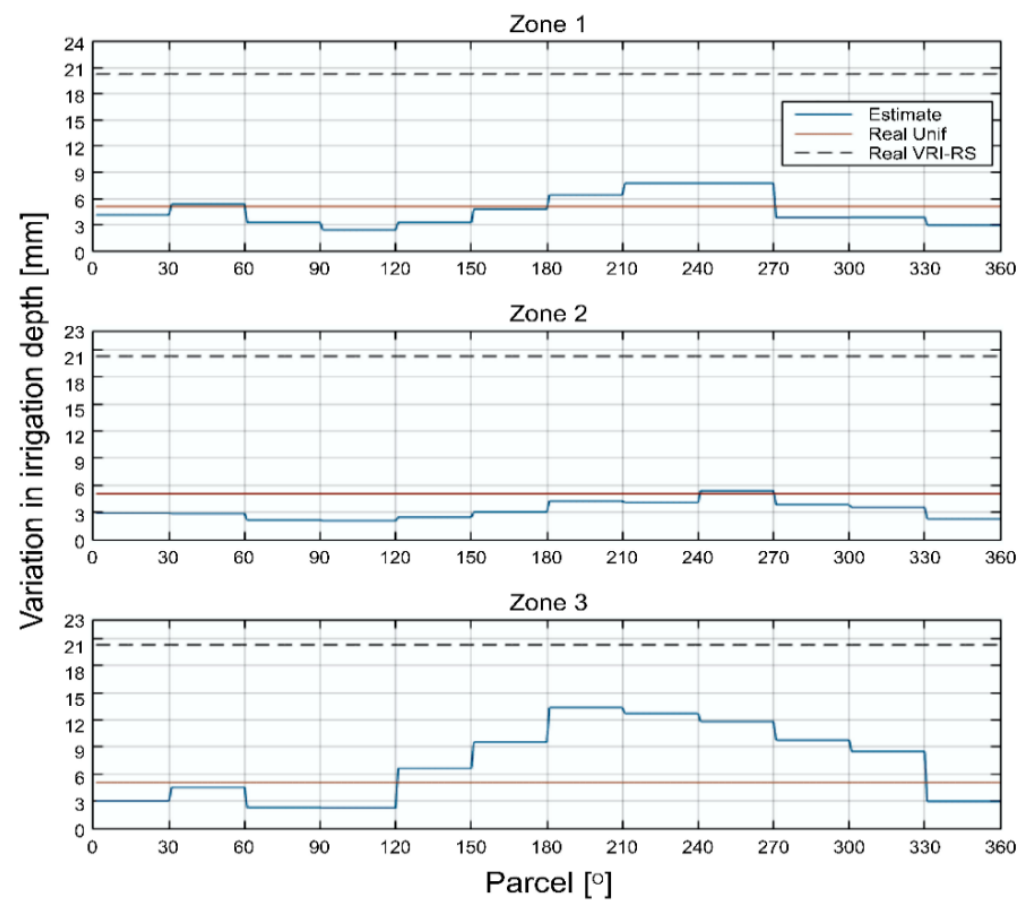

Figure 17. Estimated irrigation depth for each management zone.

The hypothesis assumed in this study was the rainfall that occurred a few days earlier. Rainfall in the Brule region was $274 \mathrm{~mm}$ from May to October and $37.08 \mathrm{~mm}(1.46$ inches) in September. Rainfall was $31 \mathrm{~mm}$ on September 6 and 7, according to the United States Climate data website. The irrigation event that occurred between August 31 and September 2 further increased the water level in the soil. Therefore, this hypothesis may explain the results found on this date.

\subsubsection{Results for September 20, 2016}

The FIS used on this date was the same used on the other dates, without further adjustments. The estimated speed varied from $46 \%$ to $76 \%$, according to the FIS (Figure 18a). In the zone located between $90^{\circ}$ and $120^{\circ}$, the variation decreased from $73 \%$ to $53 \%$. It is worth noting that on previous dates, there was no rainfall, and satellite images were cloudless. 
(a)

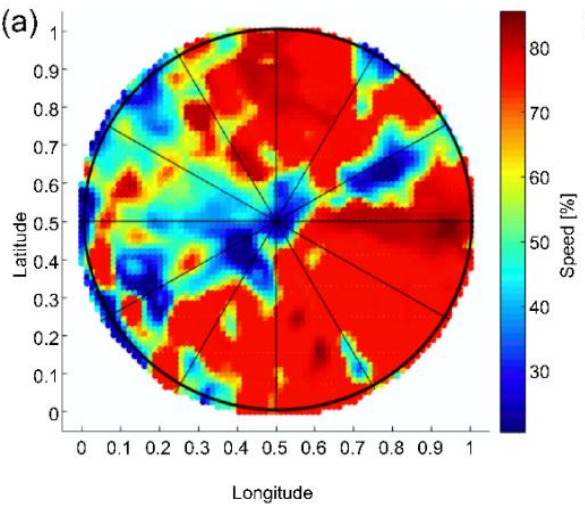

(b)

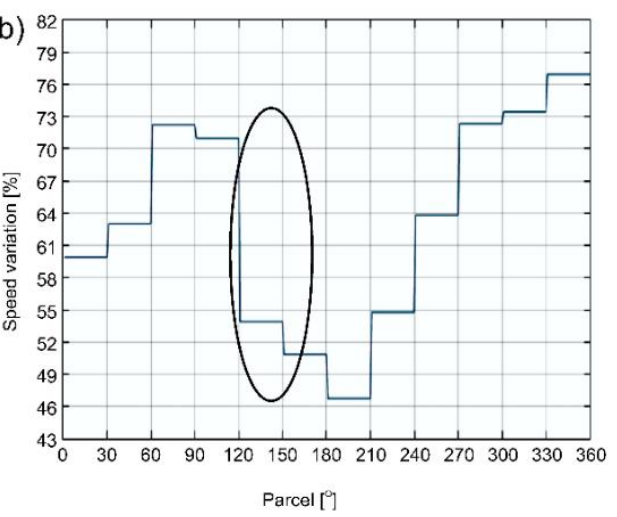

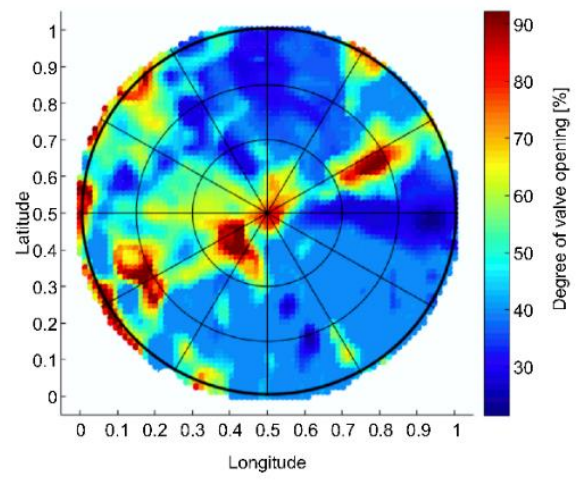

Figure 18. a) Rotation speed of the center pivot; b) Average rotation speed for each parcel; c) Degree of opening of solenoid valves

This marked variability raises an issue, which had already been detected in Ipiranga do Norte, MT, and emphasizes the need to assess whether the CPIS could estimate rotation speeds in small areas. On September 20, 2016, the degree of valve opening was negatively correlated with rotation speed, and several zones presented variability in this parameter (Figure 18c). Therefore, when the two outputs were sent to the controller, the estimated irrigation depth was expected from systems using spatially and temporally variable rates. The estimated irrigation volumes in each management zone are shown in Figure 19. 


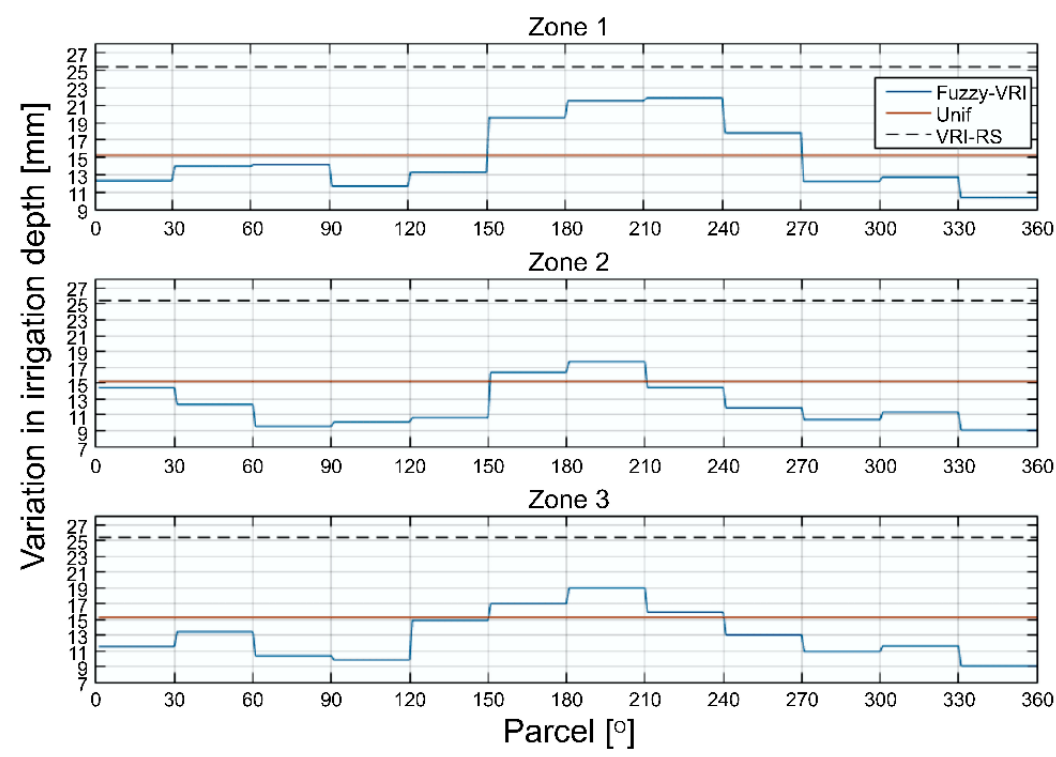

Figure 19. Estimated irrigation depth in each management zone.

The recommendations made the fuzzy-VRI system indicate that quadrant III required the highest water volume. Therefore, the sensitivity of the FIS was similar to that of the neutron probe. This result is positive because the SSM measurements made by the neutron probe are more reliable. Thus, the proposed system was successful in inferring that the cultivated area had a lower variability in SSM and therefore required a lower water volume relative to the amount estimated by the VRI-RS method proposed by [17].

\subsection{Validation of the Fuzzy-VRI Approach}

To perform a validation of the control system developed, only irrigation volume data at the study site located in Ipiranga do Norte, Mato Grosso, Brazil were used. Due to the experimental nature of the planting area in Brule, Nebraska, United States the data were not used. When comparing the results of the irrigation blade between the conventional/uniform method and the variable rate application method, it is noted that there are regions with lesser water requirements, which would lead to a reduction in water use, and thus decrease costs.

The water volume (in $\mathrm{m}^{3}$ ) used for irrigation is shown to improve the performance visualization of the FIS. The comparison between estimated and observed irrigation volumes for each sector and for each date of analysis is presented in figure 20.

For the analysis of the date of June 17, 2018, the volume used for each parcel decreased by $5-20 \%$ as shown in Figure 20 -a. If crop yield remained the same, it might be possible to claim that the fuzzy-VRI could decrease costs and expenses, such as potable water. 

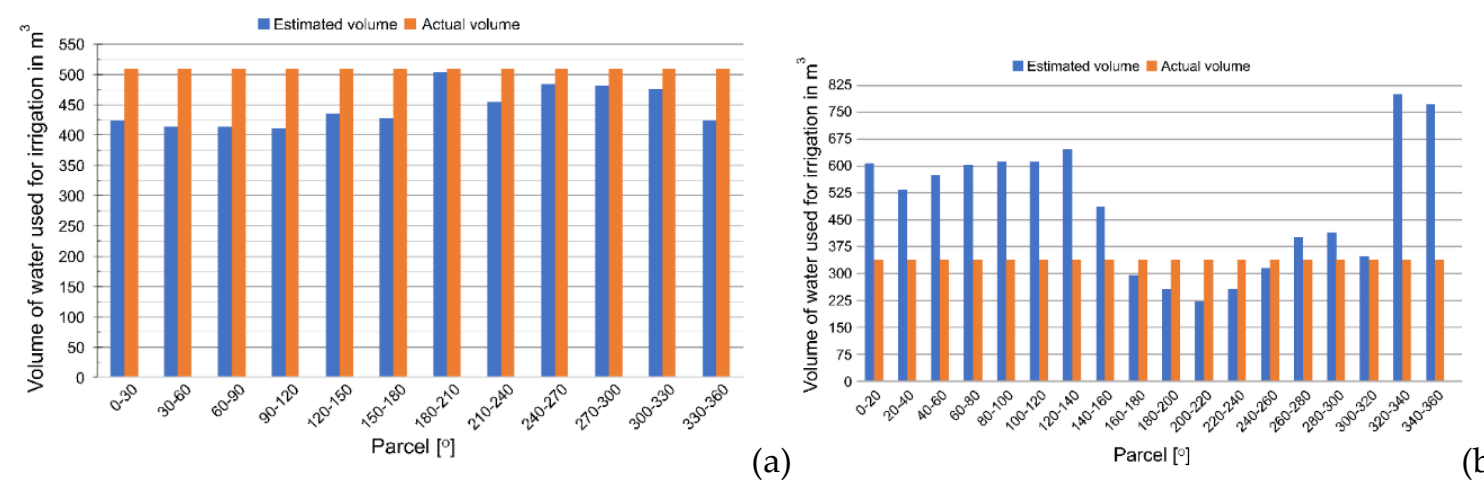

(b)

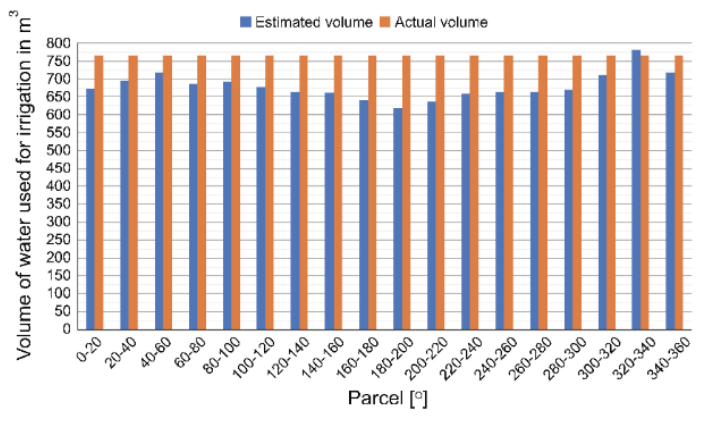

(c)

Figure 20. Comparison between estimated and observed irrigation volumes for each sector and for each date in study site located in Ipiranga do Norte: a) on June 17, 2018; b) on June 27, 2018 and c) on August 27, 2018.

The estimates for irrigation depth were slightly lower than the actual irrigation values. It is worth mentioning that the fuzzy-VRI detected regions with water deficits and distributed water accordingly, without significant differences from the actual values obtained by the commercial platform. For the analysis of the date of June 27, 2018, the strong impact of the overestimation of irrigation depth on the volume of water used is shown in Figure 20-b.

The significance of this comparison is to verify whether the low estimate in the irrigated volume generated by the fuzzy-VRI system is within an expectation. In a way, it is possible to verify that the developed system has sufficient sensitivity to infer a smaller volume. For the analysis of the date of August 27, 2018, the values per $\mathrm{m}^{3}$ of the irrigation theoretically applied by the system and the actual volume that was applied are shown in Figure 20-c. The regions of the angular range between $320^{\circ}$ to $340^{\circ}$ present values that are very close to the real ones. Although the FIS has few inputs and rules, system tuning was adequate and produced significant results.

\section{Discussion and Limitations}

This study faced several limitations. To begin with, information regarding crop characteristics was limited due to the commercial nature of the study area at the Ipiranga do Norte field site. For instance, it was not possible to determine why some regions displayed high variability and a large number of MZs, i.e., it was difficult to assess whether the MZs detected by the FIS had water deficits. This limitation will be addressed in future studies. However, it was possible to confirm that the FIS was able to detect variability in crop conditions, indicating regions with different water requirements, achieving less differences from the actual values measured by the commercial platform. The advantage of analyzing regions that are monitored by commercial irrigation systems is the high crop yield, 
as well as the expected and predictable development, thus demonstrating the advantages and disadvantages of the proposed methodology.

Further, regarding the commercial farm, the exclusive use of satellite images had disadvantages, such as a low frequency of cloudless images and limited use of the data from the remote sensing commercial tool based on the agreement with i-ekbase. Therefore, the analysis of and comparison between the MZs in Ipiranga do Norte were restricted to only eight dates. Additionally, regarding the results for June 17, 2018, the strategy of selecting the size of irrigation zones and subzones by a counterclockwise quadrant division was a disadvantage because partitioning was performed visually with the help of an operator.

A better approach would be a cluster-based approach to divide the study area automatically without human intervention. However, no commercial system currently uses this approach. This theme could be addressed in future studies. Further, the limited number of input variables was a disadvantage of the proposed system due to the lack of sensitivity likely caused by insufficient variables to indicate special variability. Additionally, in the experiments for the study area in Brule, Nebraska, United States, there were problems related to the presence of clouds at the time of data collection, which restricted the analysis and comparison of MZs to only seven dates.

The results of these experiments showed that the experimental area located in Brule presented favorable and promising characteristics, which could be analyzed in studies that adopt precision irrigation technologies. It is clear that the proposed method has typical VRI characteristics, including the spatial and temporal variability of the study sites. The fuzzy logic system appeared to be well-tuned and was effective in 1) capturing spatial variability in the crop, and 2) developing a VRI prescription map. The results underscore the need for analyzing more input variables from the study sites, allowing the FIS to infer the overall environmental characteristics of the study areas accurately, and another relevant point is the use of satellite images.

Assuming that this system works, it could also be used for uniform irrigation management (simply use the mean speed recommended by the fuzzy VRI). That is not as exciting, but so far uniform irrigation is still much more common than VRI, and we still don't have a really easy-to-use, automatic decision support system to fully automate center pivots. Perhaps the fuzzy VRI could the solution for this? If so, it would have broad applicability.

Finally, in validating the fuzzy-VRI approach, it was not possible to assess whether crop yield could be maintained regardless of the lower irrigation depth estimates relative to the actual irrigation values. Therefore, additional studies are necessary to assess production efficiency and improve this methodology.

\section{Conclusions}

The careful and efficient use of water in agriculture is critical and thus requires the use of new technologies. However, there is a lack of research and less attention -if anyhas been paid on testing the combinations of available techniques to determine the location and time of irrigation controlled by a center pivot using AI methods. The practical approach adopted in this study is innovative and is not found in the literature.

An important aspect of the proposed system is that it accurately detected management zones (MZs) using limited data. MZs are accurately detected when the system can measure the spatial and temporal variability of crop areas. The adopted method was successful given that the results met VRI criteria, and the fuzzy-VRI provided control maps for rotation speed and opening cycles for the solenoid valves of the CPISs. Several MZs were detected using a limited number of variables, including CT, SAVI, NI, and SSM. The detection of MZs was optimal when a large amount of spatial and temporal data was available. Nonetheless, the biggest challenge when working with this type of technology is obtaining this type of data from crops at a low cost. 
A relevant finding of this study is that the use of the proposed system allowed the reduction of water use in the study areas, which should stimulate further research. However, it was not possible to assess whether this method increased crop yield given that field studies were not performed. Notwithstanding, the results demonstrated that Fuzzy VRI can make easy-to-use, automatic decision support system to fully automate center pivots.

These results warrant further studies on the development of control maps for irrigation, which are more similar to field conditions. Our proposed system requires improvement by incorporating other input variables that enable interpreting the characteristics of crop areas, thus enabling fuzzy-VRI to accurately measure the water application rate while maintaining high yields.

Author Contributions: Conceptualization: Willians R.M. and Fábio M.U.; design: Willians R.M., Ritaban D., Derek M.H. and Salah E.R.; analysis: Willians R.M., Ritaban D., Derek M.H. and Salah E.R.; implementation: Willians R.M.; writing: all authors; project supervision: Fábio M.U. All authors have read and agreed to the published version of the manuscript.

Funding: This research received no external funding.

Acknowledgments: The authors thank the Federal Institute of Education, Science and Technology of Mato Grosso (IFMT) for the financial support and the Post-Graduation Program in Electrical and Computer Engineering of the Federal University of Rio Grande do Norte (PPGEEC/UFRN) for the technical and administrative support. Finally, we thank the Coordination of Improvement of Higher Education Personnel (Ministry of Education (Capes - MEC)) for granting the PRODOUTORAL scholarship to the corresponding author.

Conflicts of Interest: The authors declare no conflict of interest. The funders had no role in the design of the study; in the collection, analyses, or interpretation of data; in the writing of the manuscript; or in the decision to publish the results.

\section{References}

1. The State of Food and Agriculture: Climate Change, Agriculture and Food Security; Food and Agriculture Organization of the United Nations: Rome, 2016.

2. Christofidis, D. Water in food production: the role of irrigation in achieving sustainable development. Brasilia: University of Brasilia, 2005; p. 29.

3. Evett, S. R., P. D. Colaizzi, F. R. Lamm, S. A. O'Shaughnessy, D. M. Heeren, T. J. Trout, W. L. Kranz, and X. Lin. 2020. Past, present and future of irrigation on the U.S. Great Plains. Transactions of the ASABE (in press), doi: 10.13031/trans.13620.

4. Smith, R.J.; Baillie, J.N.; McCarthy, A.C.; Raine, S.R.; Baillie, C.P. Review of Precision Irrigation Technologies and their Application. National Centre for Engineering in Agriculture, University of Southern Queensland, Toowoomba, Technical Report, NCEA Publication, 2010.

5. O'Shaughnessy, S. A., S. R. Evett, P. D. Colaizzi, M. A. Andrade, T. H. Marek, D. M. Heeren, F. R. Lamm, and J. L. LaRue. 2019. Identifying advantages and disadvantages of variable rate irrigation - an updated review. Applied Engineering in Agriculture 35(6): 837-852, doi: 10.13031/aea.13128.

6. Stafford, J.V. The role of technology in the emergence and current status of precision agriculture. In Handbook of Precision Agriculture: Principles and Applications; Srinivasan, A. Ed.; The Haworth Press, Inc, New York, NY. 2006; pp. 19-56.

7. Evans, R.G.; LaRue, J.; Stone, K.C.; King, B.A. Adoption of site-specific variable rate sprinkler irrigation systems. Irrig Sci 2013, 31(4), 871-887. http://dx.doi.org/10.1007/s00271-012-0365-x

8. Duke, R.H.; Heermann, F.D.; Dawson, J.L. Appropriate depth of application for scheduling central pivot irrigation. Tran ASAE 1992, 35(5), 1457-1464.

9. Fraisse, C.W., Heermann, D.F., Duke, H.R. Modified linear move system for experimental water application. In Advances in Planning, Design, and Management of Irrigation Systems as Related to Sustainable Land Use, Leuven, Belgium 1993, 1, 367-376.

10. Sadler, E.J.; Camp, C.R.; Evans, D.E.; Usrey, L.J. A site-specific center pivot irrigation system for highly-variable Coastal Plain soils. In Proceedings of the Third International Conference on Precision Agriculture, 1996; Robert, P.C., Rust, R.H., Larson, W.E., Eds.; 827-834. http://dx.doi.org/10.2134/1996.precisionagproc3.c98

11. Camp, C.R.; Sadler, E.J. Center pivot irrigation system for site-specific water and nutrient management. ASAE Paper No. 941586. ASAE, St. Joseph, MI 1994. 
12. Camp, C.R.; Sadler, E.J.; Evans, D.E.; Usrey, L.J.; Omary, M. Modified center pivot irrigation system for precision management of water and nutrients. Appl Eng Agric 1998 14(1), 23-31.

13. Omary, M.; Camp, C.R.; Sadler, E.J. Center pivot irrigation system modification to provide variable water application depth. Appl. Eng. Agric. 1997, 13(2), 235-239.

14. King, B.A.; Kincaid, D.C. A variable flow rate sprinkler for site-specific irrigation management. Appl. Eng. Agric. 2004, 20(6) 765-770.

15. O'shaughnessy, S.A.; Evett, S.R.; Colaizzi, P.D. Dynamic prescription maps for site-specific variable rate irrigation of cotton. Agric. Water Manag. 2015, 159, 123-138. http://dx.doi.org/10.1016/j.agwat.2015.06.001

16. McCarthy, A.C.; Hancock, N.H.; Raine, S.R. Advanced process control of irrigation: the current state and an analysis to aid future development. Irrig. Sci. 2013, 31(3), 183-192. http://dx.doi.org/10.1007/s00271-011-0313-1

17. Barker, J.B.; Heeren, D.M.; Neale, C.M..; Rudnick, D.R. Evaluation of variable rate irrigation using a remote-sensing-based model. Agric. Water Manag. 2018, 203, 63-74. http://dx.doi.org/10.1016/j.agwat.2018.02.022

18. Steven, M.D. Correcting the effects of field of view and varying illumination in spectral measurements of crops. Precis. Agric. 2004, 5, 55-72. http://dx.doi.org/10.1023/B:PRAG.0000013620.61519.86

19. Iounousse, J., Er-Raki, S., Elmotassadeq, A., Chehouani, H. Using an unsupervised approach of Probabilistic Neural Network (PNN) for land use classification from multitemporal Satellite images. Applied Soft Computing. 2015, 30: 1-13. https://doi.org/10.1016/j.asoc.2015.01.037.

20. Coble, K.H.; Mishra, A.K.; Ferrell, S.; Griffin, T., Big Data in Agriculture: A Challenge for the Future, Applied Economic Perspectives and Policy, Volume 40, Issue 1, March 2018, Pages 79-96, https://doi.org/10.1093/aepp/ppx056.

21. Barker, J. B., S. Bhatti, D. M. Heeren, C. M. U. Neale, and D. R. Rudnick. Variable rate irrigation of maize and soybean in WestCentral Nebraska under full and deficit irrigation. Frontiers in Big Data. 2019, 2(34), doi: 10.3389/fdata.2019.00034.

22. Dutta, R.; Morshed, A.; Aryal, J.; D'este, C.; Das, A. Development of an intelligent environmental knowledge system for sustainable agricultural decision support. Environ. Modell. Softw. 2014, 52, 264-272. http://dx.doi.org/10.1016/j.envsoft.2013.10.004

23. P. Malaterre, D. Rogers, and J. Schuurmans, "Classification of canal control algorithms," Journal of Irrigation and Drainage Engineering, vol. 124, no. 1, pp. 3-10, 1998.

24. Shang, C., Chen, W. H., Stroock, A. D., \& You, F. (2020). Robust model predictive control of irrigation systems with active uncertainty learning and data analytics. IEEE Transactions on Control Systems Technology. DOI: 10.1109/TCST.2019.2916753

25. Fele, F., Maestre, J. M., Hashemy, S. M., de la Peña, D. M., \& Camacho, E. F. (2014). Coalitional model predictive control of an irrigation canal. Journal of Process Control, 24(4), 314-325.

26. Zadeh, L.A. Fuzzy sets. Information and Control 1965, 8(3), 338-353. http://dx.doi.org/10.1016/S0019-9958(65)90241-X

27. Papageorgiou, E.I.; Kokkinos, K.; Dikopoulu, Z. Fuzzy sets in agriculture. In Fuzzy Logic in Its 50th Year: New Developments, Directions and Challenges (Volume 341 of Studies in Fuzziness and Soft Computing); Kahraman C., Kaymak U., Yazici A., Eds; Springer International Publishing: 2016.; 21-58 http://dx.doi.org/10.1007/978-3-319-31093-0_10

28. Al-Faraj, A.; Meyer, G.E.; Horst, G.L. A crop water stress index for tall fescue (Festuca arundinacea Schreb.) irrigation decisionmaking - a fuzzy logic method. Comput. Electron. Agric. 2001, 32(2), 69-84. http://dx.doi.org/10.1016/S0168-1699(01)00161-2

29. Zhang, Q.; Wu, C.H.; Tilt, K. Application of fuzzy logic in an irrigation control system. Proceedings of The IEEE International Conference on Industrial Technology, 1996; 593-597.

30. Xiang, X. Design of fuzzy drip irrigation control system based on ZigBee wireless sensor network. International Conference on Computer and Computing Technologies in Agriculture IV 2011, 344, 495-501. http://dx.doi.org/10.1007/978-3-642-18333-1_58

31. Zhu, L.Z.; and LI, X. Study of automatic control system for irrigation. Advanced Materials Research 2011, $219,1463-1467$. http://dx.doi.org/10.4028/www.scientific.net/AMR.219-220.1463

32. Ed-Dahhak, A.; Guerbaoui, M.; ElAfou, Y.; Outanoute, M.; Lachhab, A.; Belkoura, L. Bouchikhi, B. Implementation of fuzzy controller to reduce water irrigation in greenhouse using labview. International Journal of Engineering and Advanced Technology Studies. 2013, 1(2), 12-22.

33. Zhang, H.Y.; Fei, L.; Wei, Z.; Congcong, M.; Yuewei, C. The fuzzy decision-making method of irrigation amount based on ET and soil water potential. International Conference on Electronics, Communications and Control (ICECC) 2011, $2927-2931$.

34. Allen, R.G.; Pereira, L.S.; Raes, D.; Smith, M. Crop evapotranspiration: Guidelines for computing crop water requirements. Rome: FAO - Irrigation and Drainage Paper, 1998, 300(9).

35. Dejonge, K. C.; Taghvaeian, S.; Trout, T. J.; Comas, L. H. Comparison of canopy temperature-based water stress indices for maize. Agricultural Water Management. 2015, 156, 51-62. https://doi.org/10.1016/j.agwat.2015.03.023 
36. Gutierrez, M.; Norton R.; Thorp, K.R.; Wang, G. Association of spectral reflectance indices with plant growth and lint yield in upland cotton. Crop Sci. 2012, 52, 849- 857. http://dx.doi.org/10.2135/cropsci2011.04.0222

37. García-Tejero, I.F.; Durán-Zuazo, V.H.; Muriel-Fernández, J.L.; Jiménez-Bocanegra, J.A. Linking canopy temperature and trunk diameter fluctuations with other physiological water status tools for water stress management in citrus orchards. Funct. Plant Biol. 2011, 38(2), 106-117. http://dx.doi.org/10.1071/FP10202

38. Gupta, M.; Srivastava, P.K.; Islam, T. Integrative use of near-surface satellite soil moisture and precipitation for estimation of improved irrigation scheduling parameters. Satellite Soil Moisture Retrieval Elsevier 2016, 271-288. http://dx.doi.org/10.1016/B9780-12-803388-3.00014-0

39. Ines, A.V.M.; Mohanty, B.P. Near-surface soil moisture assimilation for quantifying effective soil hydraulic properties using genetic algorithm: 1. Conceptual modeling. Water Resour. Res. 2008, 44(6), 1-26. http://dx.doi.org/10.1029/2007WR005990

40. Walker, J.P.; Willgoose, G.R.; Kalma, J.T. One-dimensional soil moisture profile retrieval by assimilation of near-surface observations: A comparison of retrieval methods. Adv. Water Resour. 2001, 24(6), 631-650. http://dx.doi.org/10.1016/S03091708(00)00043-9

41. Zarco-Tejada, J.; González-Dugo, V.; Berni, J.A.J. Fluorescence, temperature and narrow-band indices acquired from a UAV platform for water stress detection using a micro-hyperspectral imager and a thermal camera. Remote Sensing of Environment 2012, 117, 322-337. http://dx.doi.org/10.1016/j.rse.2011.10.007

42. Brito, G.G.; Sofiatti, V.; Brandão, Z.N.; Silva, V.B.; Silva, F.M.; Silva, D.A. Non-destructive analysis of photosynthetic pigments in cotton plants. Acta. Sci. Agron. 2011, 33(4), 671-678. http://dx.doi.org/10.4025/actasciagron.v33i4.10926

43. Fageria, N.K.; Baligar, V.C. Enhancing nitrogen use efficiency in crop plants. Adv. Agron. 2005, 88, 97-185. http://dx.doi.org/10.1016/S0065-2113(05)88004-6

44. Rathke, G.W.; Christen, O.; Diepenbrock, W. Effects of nitrogen source and rate on productivity and quality of winter oilseed rape (Brassica napus L.) grown in different crop rotations. Field Crops Res., 2005, 94(2-3) 103-113. http://dx.doi.org/10.1016/j.fcr.2004.11.010

45. Mamdani, E.H.; Assilian, S. An experiment in linguistic synthesis with a fuzzy logic controller. International Journal of ManMachine Studies 1975, 7(1), 1-13. http://dx.doi.org/10.1016/S0020-7373(75)80002-2

46. Ross, T.J. Fuzzy Logic with Engineering Applications; McGraw-Hill: 1995.

47. Pedrycz, W. Why triangular membership functions? Fuzzy Sets and Systems 1994, 64, 21-30.

48. Pedrycz, W. and Gomide, F. An introduction to fuzzy sets: Analysis and design. MIT Press: Cambridge, England, 1998.

49. Mendes W.R., Araújo F.M.U., Dutta R., Heeren D.M. Fuzzy control system for variable rate irrigation using remote sensing. Expert Syst. Appl. 2019; 124:13-24. doi: 10.1016/j.eswa.2019.01.043.

50. Bernardo, S.; Soares A.A.; Mantovani, E.C. Irrigation Manual, 8th edition, University Press, Viçosa,2006; p. 625.

51. Silva, E.M. da; Azevedo, J.A. de. Design of the central pivot irrigation side. Planaltina: EMBRAPA-CPAC, 1998 ; p. 54.

52. Phocaides, A. Handbook on Pressurized Irrigation Techniques. Food and Agriculture Organization of The United Nations: Rome, Italy, 2007.

53. Hezarjaribi, A. Site-specific Irrigation: Improvement of Application Map and a Dynamic Steering of Modified Center Pivot Irrigation System. Doctoral Theses of Agricultural Sciences, Institute of Production Engineering and Building Research Braunschweig, Germany, 2008.

54. Moreno, M.A.; Medina, D.; Ortega, J.F.; Tarjuelo, J.M. Optimal design of center pivot systems with water supplied from wells. Agric. Water Manag. 2012, 107, 112-12. http://dx.doi.org/10.1016/j.agwat.2012.01.016

55. Haghverdi, A.; Leib, B.G.; Washington-Allen, R.A.; Buschermohle, M.J.; Ayers, P.D. Studying uniform and variable rate center pivot irrigation strategies with the aid of site-specific water production functions. Comput. Electron. Agric. 2016, 123, 327-340. http://dx.doi.org/10.1016/j.compag.2016.03.010

56. Colaizzi, P.D.; O'Shaughnessy, S.A.; Evett, S.R.; Mounce, R.B. Crop evapotranspiration calculation using infrared thermometers aboard center pivots. Agric. Water Manag. 2017, 187, 173-189. http://dx.doi.org/10.1016/j.agwat.2017.03.016

57. Sui, R.; Yan, H. Field study of variable rate irrigation management in humid climates. Irrig. Drain. 2017, 66(3), 327-339. http://dx.doi.org/10.1002/ird.2111

58. Shi, X.; Han, W.; Zhao, T.; Tang, J. Decision support system for variable rate irrigation based on UAV multispectral remote sensing. Sensors 2019, 19(3), 2880-2900. http://dx.doi.org/10.3390/s19132880

59. Gegov, A.E.; Frank, P.M. Hierarchical fuzzy control of multivariable systems. Fuzzy Sets and Systems 1995, 72(3), 299-310. http://dx.doi.org/10.1016/0165-0114(94)00293-G 
60. Ge, A.; Wang, Y.; Liu, Z.; Jiang, P. Hierarchical fuzzy control of multivariable systems via semi-tensor product method. Proceedings of the 33rd Chinese Control Conference, Nanjing, China, 2014; 4551-4556. http://dx.doi.org/10.1109/ChiCC.2014.6895705

61. Takagi, T.; Sugeno, M. Fuzzy identification of systems and its applications to modeling and control. IEEE Trans. Systems Man Cybern. 1985, 15(1), 116-132. http://dx.doi.org/10.1109/TSMC.1985.6313399

62. Sugeno, M.; Kang, G.T. Structure identification of fuzzy model. Fuzzy Sets and Systems 1988, 28(1), 15-33. http://dx.doi.org/10.1016/0165-0114(88)90113-3

63. Yang, C.C.; Prasher, S.O.; Landry, J.A.; Ramaswamy, H.S. Development of an image processing system and a fuzzy algorithm for site-specific herbicide applications. Precis. Agric. 2003, 4(1), 5-18.

64. Pulido-Calvo, I.; Gutierez-Estrada, J.C. Improved irrigation water demand forecasting using a soft-computing hybrid model. Biosyst. Eng. 2009, 102(2), 202-218. http://dx.doi.org/10.1016/j.biosystemseng.2008.09.032

65. Kweon, G. Delineation of site-specific productivity zones using soil properties and topographic attributes with a fuzzy logic system. Biosyst. Eng. 2012, 112(4), 261-277. http://dx.doi.org/10.1016/j.biosystemseng.2012.04.009

66. Dubois, D.; Prade, H. A review of fuzzy set aggregation connectives. Inform. Sciences 1985, 36(1-2), 85-121. http://dx.doi.org/10.1016/0020-0255(85)90027-1

67. Robock, A. Hydrology, Floods and Droughts: Soil Moisture. In Encyclopedia of Atmospheric Sciences, 2nd ed.; Academic Press: 2015; pp. 232-239. 